\title{
A longitudinal perspective on the effects of Covid-19 on students' resilience. The Effect of the pandemic on the reading and mathematics achievement of 8th and 5th graders in Italy
}

\author{
Francesca Borgonovi* Alessandro Ferrara ${ }^{\dagger}$
}

February 3, 2022

\begin{abstract}
We examine the effect of Covid-19 on students' achievement in mathematics and reading in primary and lower secondary schools in Italy. We use longitudinal, population level data from the INVALSI assessment. We compare the math and reading achievement of students in grades 5 and 8 in academic year 2020-21 with the achievement of students in the same grades in 2018-19 (no administration took place in academic year 2019-20). We find that on average, the grade 5 Covid-cohort experienced small increases in math and reading achievement compared to the grade 5 Non-Covid cohort. By contrast, the grade 8 Covidcohort experienced a sizeable reduction in math achievement and a smaller reduction in reading achievement compared to the Non-Covid cohort. We explore heterogeneity by students' level of prior achievement, socio-economic status, gender and province of residence. The negative effects of the pandemic were generally greater for previously low achieving students, many of whom had a disadvantaged socio-economic condition. However, the pandemic reduced SES differentials in math and reading achievement among students with equal achievement and this effect was especially pronounced among higher achieving students. It also reduced gender gaps in mathematics among higher achievers in grade 8. At the national level, the pandemic reduced to a larger degree the achievement of students living in Northern provinces, where pre-pandemic achievement was higher. At the local level, the pandemic led to increases in achievement disparities in the South, where effects were either positive or less negative among the highest achievers, but it led to reductions in achievement disparities in the North because the effects were mostly concentrated among highest achievers.
\end{abstract}

Keywords: learning loss, Covid-19; achievement; socio-economic disparities; gender disparities; INVALSI

\footnotetext{
*UCL Social Research Insitute. f.borgonovi@ucl.ac.uk

†European University Institute, Department of Political and Social Sciences. alessandro.ferrara@eui.eu
} 


\section{Introduction}

The Covid-19 pandemic caused significant disruptions to the everyday lives of people around the world. In an attempt to limit the spread of the disease and protect children's right to education, governments imposed school closures but maintained teaching and learning through remote learning opportunities (OECD, 2021b). Learning and instruction were adapted to a setting in which, absent face-to-face contact, children communicated to their peers and their teachers online or by phone and learning was provided through digital resources, and, at times, radio or television (Andrew et al., 2020; Grewenig et al., 2021). Despite marked increases in the adoption of Information and Communication Technologies (ICTs) in education in the past decade (Borgonovi and Pokropek, 2021), many schools struggled to provide adequate online learning solutions (Kuhfeld et al., 2020). Teachers and school principals in many countries lamented lack of preparation but also equipment for themselves and for their students, especially students from socio-economically disadvantaged households and living in deprived communities (World Bank et al., 2021).

Disruptions from school closures and the difficult transition to distance learning were compounded by other burdens imposed by the pandemic, with especially severe effects on some children. Economic uncertainty, unemployment, and changing working arrangements disproportionately affected certain groups in society, with repercussions on parents' ability to supervise and provide for their children's needs (Adams-Prassl et al., 2020). Children with a disadvantaged condition may have been especially susceptible to learning disruptions as a result of social isolation and its effects on academic motivation (Zaccoletti et al., 2020), mental and physical health (Golberstein et al., 2020). Finally, there is evidence that school closures led to reduced learning time especially among low achievers and socio-economically disadvantaged students (Andrew et al., 2020; Bayrakdar and Guveli, 2020; Grätz and Lipps, 2021; Grewenig et al., 2021).

Several studies have documented the negative effects of school closures during the first wave of the pandemic on student achievement (see Thorn and Vincent-Lancrin (2021) and Hammerstein et al. (2021) for reviews). In general, they suggest heterogeneous effects across countries and groups, with negative impacts being larger for younger children (Tomasik et al., 2021) for children from socio-economically disadvantaged families (Maldonado and De Witte, 2021; Engzell et al., 2021); for low-performing students in mathematics achievement and for high-performing students in reading achievement (Schult et al., 2021).

In this paper, we contribute to the emerging literature on the educational consequences of the pandemic by investigating the case of Italy, one of the countries most severely hit by Covid19 (Johns Hopkins, 2022) and where schooling was very disrupted (World Bank et al., 2021). We examine the cumulative effect of pandemic-related disruptions during the first two waves of the pandemic (between March 2020 and May 2021) on students' mathematics and reading achievement in primary and lower secondary schools using longitudinal population data from the Italian National Institute for the Evaluation of the Education System (INVALSI). Primary and lower-secondary schools remained closed from March 2020 until the end of the 2019-20 
academic year and, in some communities, for long stretches of the 2020-21 academic year.

Our aim is to identify the effects of the pandemic on inequalities in reading and mathematics achievement. The first dimension of inequality that we consider is the geographical dimension. In Italy geographical disparities in learning outcomes are especially marked, with students in some Northern regions achieving at levels that are comparable to those obtained by the best students in the world and students in some Southern regions achieving well below the OECD average (OECD, 2016). Second, we consider socio-economic inequalities. Like in many other countries, in primary and lower secondary schools advantaged students in Italy achieve at higher levels than their disadvantaged counterparts (Mullis et al., 2017, 2020). Third, we consider gender inequalities. Gender differences in favour of boys in mathematics are especially marked and tend to emerge earlier in Italy than in other countries (Contini et al., 2021). Finally, we consider if the pandemic was especially detrimental to the learning trajectory of those who, before the pandemic, were high or low achievers.

We rely on INVALSI data from cohorts of students who had sat their end of primary and end of lower-secondary school evaluations before the pandemic (in Spring 2019) and compare their achievement with the achievement of those cohorts who sat the same evaluations after the pandemic, in Spring 2021. We estimate the overall difference in achievement between the prepandemic and the post-pandemic cohorts as well as the difference in the effect of the pandemic for students living in different provinces and with different previous academic achievement, socio-economic status, and gender. In particular, we are interested in examining the effects of the pandemic on students who, before the pandemic hit, had high levels of achievement despite having a socio-economically disadvantaged background. These are students who are generally referred to as being academically resilient in the literature (Agasisti et al., 2018). Similarly, we are interested in examining the effects of the pandemic on the mathematics achievement of those girls who, before the pandemic hit, defied stereotypes and had high levels of math achievement.

\section{The effect of the pandemic on achievement disparities}

A key concern of education specialists and policy makers is that government responses to limit the spread of the Sars-Cov-2 virus will have long-term effects on children's ability to fulfill their potential, with possible repercussions on economic growth, social mobility and inequalities. It is a widespread fear that, by reducing face-to-face in-person schooling, the pandemic might have widened educational inequalities in the short-term and will broaden economic inequalities in the long term. Estimating the effect of disruptions to school-based learning on academic outcomes and inequalities is key to prioritize and tailor policy interventions.

The first dimension we examine in our work is the effect of the pandemic on socio-economic inequalities in educational achievement. Despite the stated goal of policy makers worldwide since the 1960s of ensuring that schools create equal opportunities, an extensive literature documents that historically the achievement of students has reflected, to a large extent, the socio-economic condition of their family of origin (Coleman et al., 1966; Jencks et al., 1972; 
Reardon, 2014; Sirin, 2005).

There is a longstanding sociological debate on whether schooling magnifies or compensates for socio-economic disparities in educational outcomes (Marks et al., 2006; Downey and Condron, 2016; Downey et al., 2018; Skopek and Passaretta, 2021). Although the compensatory hypothesis has gained significant empirical support (Downey and Condron, 2016; Downey et al., 2004), recent scholarship has found the equalization effects of schooling to be weak or null (Passaretta and Skopek, 2021; von Hippel et al., 2018). As a result, theoretical considerations and previous empirical findings offer contrasting hypotheses on the expected impact of educational disruptions due to the pandemic on educational inequalities.

If in normal times the educational advantage of high socio-economic status (SES) students stems from the higher quality schooling they receive and their greater ability to make the most of school-based learning opportunities, the pandemic might have widened inequalities in outcomes depending on the extent to which such 'schooling advantage' was maintained during pandemic-related disruptions. First, the pandemic might have equalised the quality of schooling inputs by lowering the quality experienced by the most well-off so that it matched the quality experienced by the least well-off. In this case, students who benefited from higher quality schooling before the pandemic would be expected to experience the largest learning losses due to the pandemic. Second, reduced schooling implies a greater salience of home learning environments, which, in normal circumstances, tends to favour high SES students (Conger and Donnellan, 2007). The pandemic could have had led to less negative outcomes among high SES students because of their parents' greater ability to invest time and knowledge in their education (Schaub, 2010; Domina, 2005; Lareau, 2002).

Evidence suggests that during the first lockdown, high-SES parents spent more time supporting their children with academic work (Andrew et al., 2020) and invested more in educational and cultural resources (Bol, 2020; Jæger and Blaabæk, 2020). Nonetheless, many of the enriching extra-curricular activities that in normal times socio-economically advantaged students engage in (Dumais, 2006; Lareau, 2003) and that may explain SES disparities in achievement (Covay and Carbonaro, 2010; Agasisti et al., 2021) were banned because of pandemic-related regulations, potentially lowering inequalities in outcomes resulting from pandemic-related disruptions.

The second dimension that we examine is gender differences. The historical gender gap in educational attainment in favour of males (Goldin et al., 1870) has now been closed (and often reversed) in most advanced economies (OECD, 2021a), but women remain under-represented among those who study in science, technology, mathematics and engineering (STEM) (Card and Payne, 2021; Flabbi, 2012). The literature indicates that the beliefs parents, teachers and peers hold have the potential to shape how well boys and girls do in different academic subjects (Cornwell et al., 2012; Buchmann et al., 2008; Fryer and Levitt, 2009; Robinson-Cimpian et al., 2014; Bhanot ${ }_{*}$ and Jovanovic, 2009; Bleeker and Jacobs, 2004).

By disrupting schooling, the pandemic could have widened gender gaps in mathematics in favour of boys if teachers and educators acted in ways that reduced the influence of stereotypes before the pandemic hit, i.e. if schools were equalising forces before the pandemic. By contrast, 
it might have led to a reduction in the extent to which stereotypes shape achievement differentials if schools and the daily interactions with peers that occur at school did not contribute meaningfully to the reduction of stereotypes or even reinforced them (OECD, 2015).

We examine geographic differences in the effects of the pandemic on achievement inequalities because Italy is a country with large territorial differences in socio-economic composition, cultural norms, in the returns to educational investments, in the quality of schooling and how severely pandemic-related disruptions affected the life of children and adults (OECD, 2016). Furthermore, the effects of pandemic-related disruptions could differ meaningfully by age group, level of initial achievement and academic domain, so we compare results across these variables in our analyses.

\section{Data and Methods}

We use data from the Italian National Institute for the Evaluation of the Education System (INVALSI). INVALSI administers annual population level evaluations of students' achievement in reading and mathematics. The assessments take the form of an annual census administered in the Spring, and participation is compulsory for all students attending grade 2,5 and 8 . The INVALSI assessments are low-stakes assessments since results have no bearing for students' academic progression or grades. We investigate students' results in the grade 5 and 8 assessments for data availability reasons and because these represent key transitions at the end of primary education and lower-secondary (compulsory) education.

The INVALSI assessment was not administered for the cohorts of 2019-2020 because schools were closed. Therefore, we focus on the grade 5 and 8 cohorts who sat the INVALSI test in June 2021 (henceforth "Covid cohorts"). These cohorts experienced fully remote schooling in the last part of academic year 2019-20 as well as localised closures, possible quarantines and sickness in academic year 2020-21. To measure the impact of these disruptions, we compare the achievement of Covid cohorts with the achievement of the last cohorts of students to be assessed by INVALSI before the pandemic - the 2018-2019 grade 5 and 8 cohorts (henceforth "Non-Covid cohorts").

Thanks to the availability of individual-level longitudinal information of participants in the INVALSI tests, we are able to control for students' performance mathematics and reading in the Covid and Non-Covid cohorts before the pandemic by using students' achievement in the previous INVALSI assessment they sat (so in grade 2 for students we examine in grade 5 , and in grade 5 for students we examine in grade 8 - see Table 1 ). Since INVALSI scales only became comparable in academic year 2017-2018, we can only compare performance outcomes within grades and across cohorts, but and not across grades over time. In other words, we can compare achievement in grade 5 and 8 in the Covid and Non-Covid cohorts but we cannot estimate the difference in achievement growth between grade 5 and grade 8 for the Covid and Non-Covid cohorts. These data limitations imply that we cannot implement a standard difference in differences approach. However, by standardizing students' initial achievement within cohorts, we can examine changes in achievement for students of different levels of relative previous 
achievement.

Table 1: Description of cohorts and design

\begin{tabular}{|c|c|c|}
\hline $\begin{array}{c}\text { Academic } \\
\text { year }\end{array}$ & Covid cohorts & Non-Covid cohorts \\
\hline $\begin{array}{l}2020-21 \\
2019-20\end{array}$ & \multirow{4}{*}{$\begin{array}{c}\text { Performance Outcome (grade } 5 / 8 \text { ) } \\
- \\
\text { Previous Performance Control (grade } 2 / 5 \text { ) }\end{array}$} & \\
\hline 2018-19 & & Performance Outcome (grade $5 / 8$ ) \\
\hline 2017-18 & & - \\
\hline $\begin{array}{l}2016-17 \\
2015-16\end{array}$ & & Previous Performance Control (grade $2 / 5$ ) \\
\hline
\end{tabular}

We investigate heterogeneity in the effects of Covid-19 by socio-economic status and gender. As an indicator of socio-economic status, we use the composite ESCS index which was developed by INVALSI. It reflects the educational attainment and occupational status of the respondents' parents as well as the resources that are available in the respondent's household. We consider differences in the effects of the pandemic across four quartiles of the ESCS index. We define quartiles using the ESCS distribution in the baseline year for the grade 8 cohorts and in the outcome year for the grade 5 cohorts. This means for that for the grade 8 cohorts, we calculate quartiles of ESCS based on the ESCS students had reported when they were in grade 5 , while for the grade 5 cohorts we calculate their quartile of ESCS based on the ESCS they reported when they were in grade 5. Ideally we would have used ESCS observed at baseline for both cohorts but the ESCS indicator is not available for grade 2 students. The choice of considering ESCS at baseline is motivated by the fact that for some students the pandemic might have had a transitory effect on some dimensions of the ESCS index (such as, for example, parental occupation or availability of a quiet room to study) rendering comparisons between the Covid and Non-Covid cohorts problematic. In the Appendix we present results based on the indicator of parental education reported by students at baseline in all cohorts. Although parental education is a cruder measure of socio-economic status, it is available in all cohorts and is less susceptible to pandemic-related upheavals.

School closures affected students in different areas to a different degree, since in the 2020-21 academic year closures reflected the local evolution of the pandemic and local decision making. For example, students in the Calabria region experienced a considerably longer closure of schools than students in Veneto or Piedmont. Furthermore, achievement levels as well as socio-economic conditions differ markedly across different regions in Italy. We include province fixed effects in all our models to account for differences in the evolution of the pandemic, pervasiveness of school closures and other underlying differences. Furthermore, we estimated differential effects by province by fitting all our models on each of the 107 Italian provinces in our data. In order to account for the nested nature of our data, we estimated clustered standard errors according to the class students attended in the year in which their outcome was evaluated (grade 5 or 8). All models control for students' gender and socio-economic status.

Even though our study is based on the comparison of repeated assessments of the whole population of students who completed a grade, not all students take part in the test. Some students are retained between the grades in which INVALSI tests are administered. Although 
this is relatively uncommon in primary education, it could be more problematic for lowersecondary education results. Some students are sick or are absent from school on the day of the test. Furthermore, as all longitudinal studies, our study could be affected by attrition as children moved to a different country or had wrongfully assigned IDs.

Since we aim to measure the impacts of the pandemic accounting for previous academic achievement, students' scores in the previous INVALSI assessment they sat is a key variable in our study. For this reason, we only consider students that we could match with the previous INVALSI wave they sat, so grade 2 for students we observe in grade 5 and grade 5 for those we observe in grade 8 . In other words, our analytical samples consist of students that we were able to observe in both grade 2 and grade 5 , and in both grade 5 and grade 8 . Table 2 shows how analytical samples were obtained from initial samples by progressively dropping students with missing information for key variable (see Table A1 in the Appendix for the same results separated for Covid and Non-Covid cohorts. Table 3 shows that the Covid and Non-Covid cohorts of students from grades 5 and 8 are similar in terms of all covariates, except for SES. The grade 5 Covid cohort was slightly positively selected in terms of the ESCS indicator and the the grade 8 Covid cohort was slightly negatively selected compared to the same grade Non-Covid cohorts.

Table 2: Description of Initial and Analytical Samples

\begin{tabular}{l|c|c|c|c|}
\hline \multirow{2}{*}{ Sample (N) } & \multicolumn{2}{|c|}{ Grade 5 } & \multicolumn{2}{c|}{ Grade 8 } \\
& Math & Reading & Math & Reading \\
\hline Full & 985,909 & 985,909 & $1,070,611$ & $1,070,611$ \\
\hline Excluding attrition from previous wave & 894,015 & 894,015 & 920,899 & 920,899 \\
\hline Excluding missing outcome & 857,819 & 849,704 & 918,432 & 915,665 \\
\hline Excluding missing previous achievement & 830,620 & 829,769 & 883,913 & 892,603 \\
\hline Excluding missing ESCS & 829,143 & 823,217 & 881,372 & 876,398 \\
\hline Analytical sample & 829,120 & 823,190 & 881,359 & 876,385 \\
\hline Percent of original (\%) & $84 \%$ & $83 \%$ & $82 \%$ & $82 \%$ \\
\hline
\end{tabular}

Table 3: Describing the Covid and Non-Covid Cohorts

\begin{tabular}{|c|c|c|c|c|c|c|}
\hline & $\begin{array}{l}\text { Covid cohort } \\
(\mathrm{N}=402,205)\end{array}$ & $\begin{array}{c}\text { Grade } 5 \\
\text { Non-Covid Cohort } \\
(\mathrm{N}=434,096)\end{array}$ & Diff & $\begin{array}{l}\text { Covid cohort } \\
(\mathrm{N}=424,323)\end{array}$ & $\begin{array}{c}\text { Grade } 8 \\
\text { Non-Covid Cohort } \\
(\mathrm{N}=432,853)\end{array}$ & Diff \\
\hline Previous math achievement & 0.02 & 0.02 & -0.00 & 0.03 & 0.04 & 0.00 \\
\hline Previous reading achievement & 0.03 & 0.02 & -0.00 & 0.04 & 0.05 & 0.00 \\
\hline Female & 0.49 & 0.49 & 0.00 & 0.49 & 0.50 & 0.00 \\
\hline ESCS indicator & 0.14 & 0.05 & $-0.09^{* * *}$ & 0.05 & 0.09 & $0.04^{* * *}$ \\
\hline
\end{tabular}

Notes: Previous scores are standardized to have a mean of zero and a standard deviation of one in their respective grades and cohorts. ESCS is the INVALSI index of Economic, Social and Cultural Status. The Covid cohorts identify students for whom the achievement outcome in grade 5 or grade 8 was measured in 2020-2021.

Source: INVALSI 2015-2016, 2017-2018, 2018-2019 and 2020-2021 (grades 2, 5, 8).

\section{Main findings}

\section{Mathematics scores}

We report results of our analyses on mathematics achievement in grades 5 and 8 in Figure 1 and Figure 2 (for coefficients see Table A2, Figure A1 and Figure A2 in the Appendix). Figure 1 
indicates that, on average, the grade 5 Covid cohort experienced a small (1.6 point) increase in math achievement compared to the grade 5 Non-Covid cohort and that the grade 8 Covid cohort experienced a 7-point reduction in levels of math achievement compared to the Non-Covid cohort (the equivalent of about $70 \%$ of children's expected secondary school yearly learning gain - see Avvisati and Givord (2021)). However, Figure 2 highlights important geographic differences in the effects of the pandemic on math achievement. Provinces highlighted in red experienced the least negative impact (or, indeed, a positive impact) while provinces highlighted in blue experienced the most negative impact because of the pandemic. Figure 2 indicates that the positive effect on math achievement at grade 5 was especially marked in the South, while in Northern provinces the effect of the pandemic was strongly negative among grade 5 students. The figure shows a similar pattern for grade 8, although the North-South divide is quantitatively weaker and there is a higher degree of heterogeneity in effects within regions.

Figure 1: The impact of being in the Covid cohort and previous math scores on math achievement
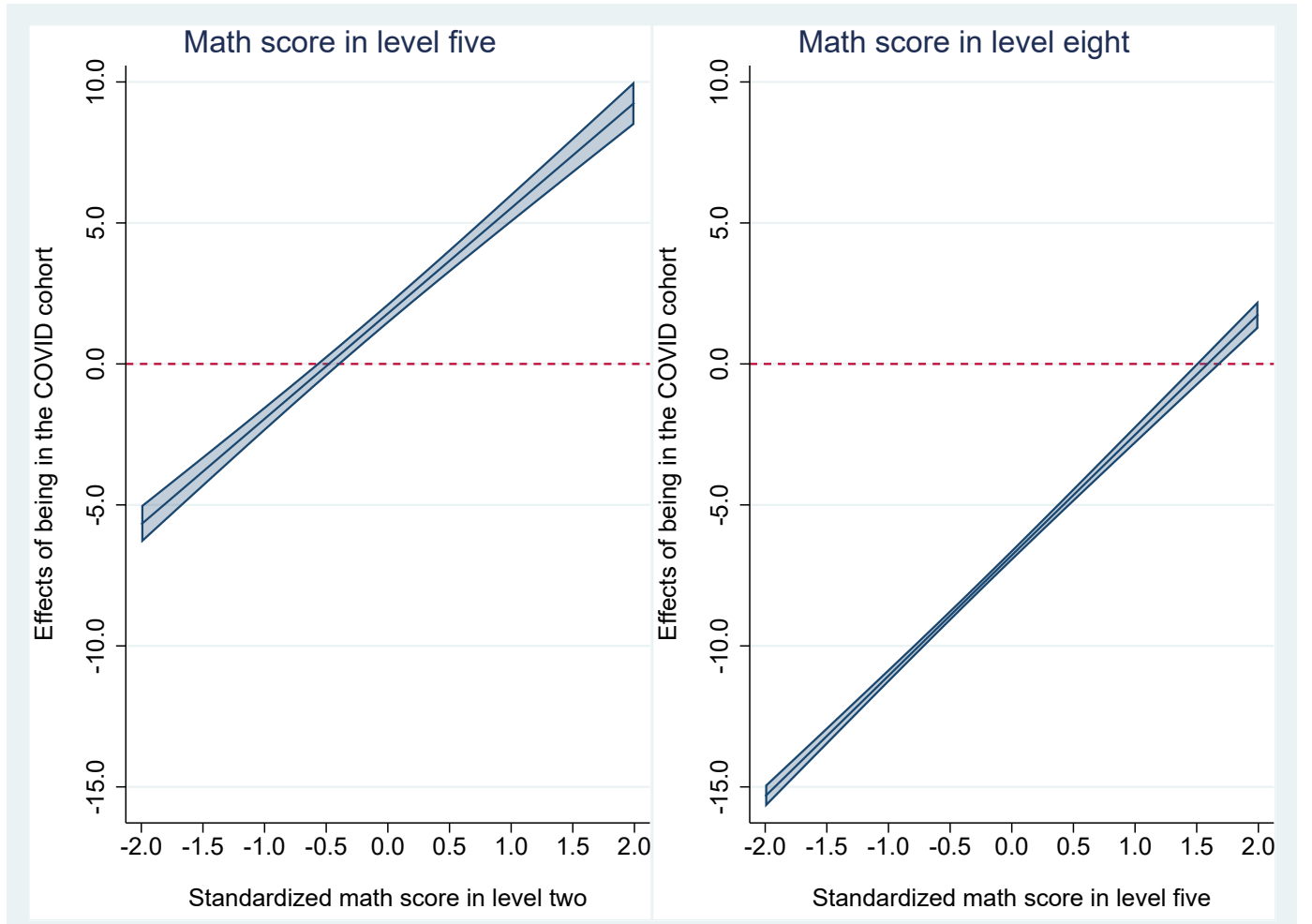

Notes: Results from models comparing the Covid cohorts and the Non-Covid cohorts controlling for students' gender, standardized scores in the previous INVALSI test, the ESCS indicator, province fixed effects and the interaction between an indicator for being in the Covid cohort and standardized scores in the previous INVALSI test. The Covid cohort identifies students for whom the achievement outcome in grade 5 or grade 8 was measured in 2020-2021. Scores in the previous INVALSI test are standardized to have a mean of zero and a standard deviation of one in their respective grades and cohorts. Results are presented with $95 \%$ confidence intervals obtained by clustering students within classrooms they attended in the year where outcomes are measured.

Source: INVALSI 2015-2016, 2017-2018, 2018-2019 and 2020-2021 (grades 2, 5, 8). 
Figure 2: The impact of being in the Covid cohort on math achievement

Impact of being in COVID cohort on 5th grade math results

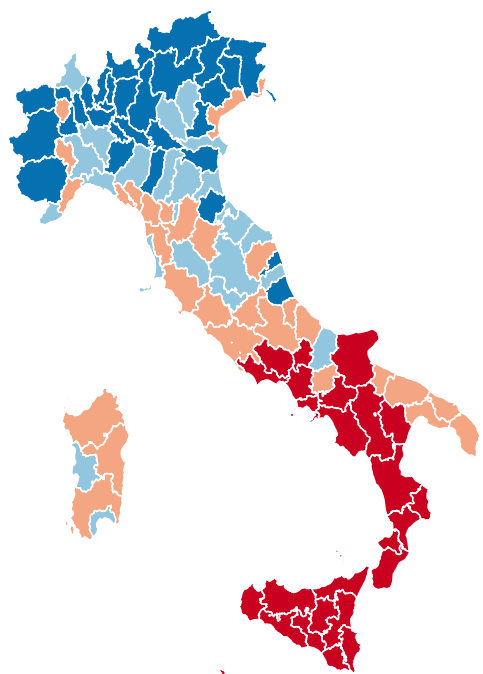

Impact of being in COVID cohort on 8th grade math results

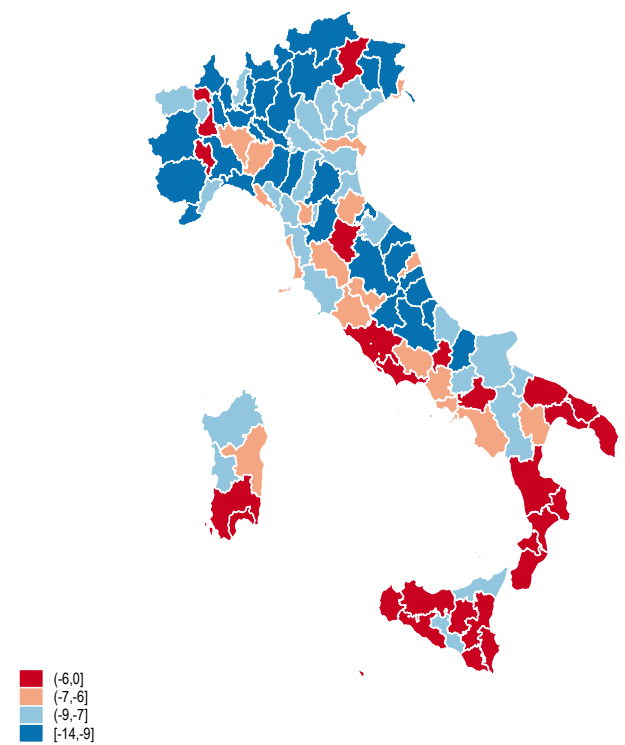

Notes: Results from models comparing the Covid cohorts and the Non-Covid cohorts controlling for students' gender, standardized scores in the previous INVALSI test, and the ESCS indicator, run separately for each province. The Covid cohort identifies students for whom the achievement outcome in grade 5 or grade 8 was measured in 2020-2021. Scores in the previous INVALSI test are standardized to have a mean of zero and a standard deviation of one in their respective grades and cohorts.

Source: INVALSI 2015-2016, 2017-2018, 2018-2019 and 2020-2021 (grades 2, 5, 8).

Results presented in Figure 1 also indicate that, on average, the pandemic led to widening achievement disparities in mathematics since negative effects were significantly larger for previously low achievers than high achievers. For example, on average we predict that grade 5 students in the Covid cohort whose math achievement in grade 2 had been 1 SD below the average of their cohort had scores that were 2 points below those obtained by their peers in the Non-Covid cohort. By contrast, grade 5 students in the Covid cohort whose math achievement in grade 2 had been $1 \mathrm{SD}$ above the average of their cohort had scores that were over 5 points above those obtained by their peers in the Non-Covid cohort. We identify a similar gradient among grade 8 students. Figure 1 illustrates that among high-achieving 8th graders (1 SD above the mean) the pandemic led to a decline of only 2.5 points but among low achieving 8 th graders (1 SD below the mean) the decline corresponded to 11 points.

Just as Figure 2 illustrates large geographic differences in the average effects of the pandemic on math achievement, results in Figure 3 illustrate that the extent to which the effect of the pandemic differed depending on prior achievement is not the same across Italian provinces. In particular, the pandemic appears to have magnified achievement disparities in Southern provinces but reduced achievement disparities in Northern provinces. For example, in the province of Trieste, 5 th grade low achievers (1 SD below the mean) experienced a reduction in their math scores that was 4-point lower compared to average performers in the Covid cohort. By contrast, in Bari, where on average the Covid cohort had higher scores than the Non-Covid 
cohort, the scores of previously low achievers increased by 4 points less than the scores of average performers in the Covid cohort.

Figure 3: The impact of being in the Covid cohort and previous math scores on math achievement, by province

Covid cohort * previous performance and 5 th grade math results

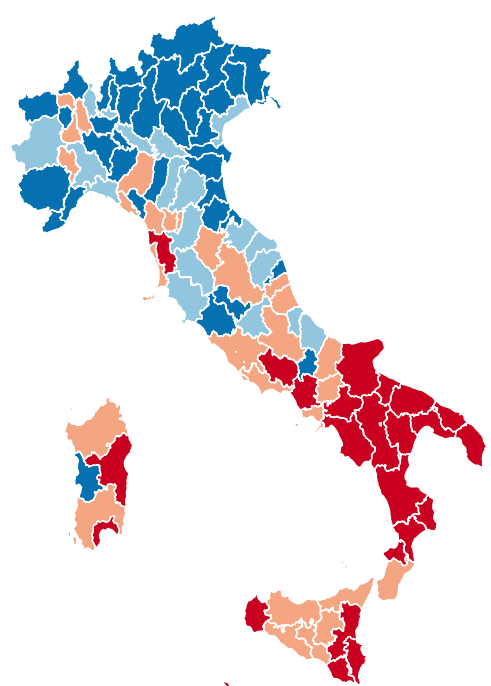

Covid cohort * previous performance and 8th grade math results

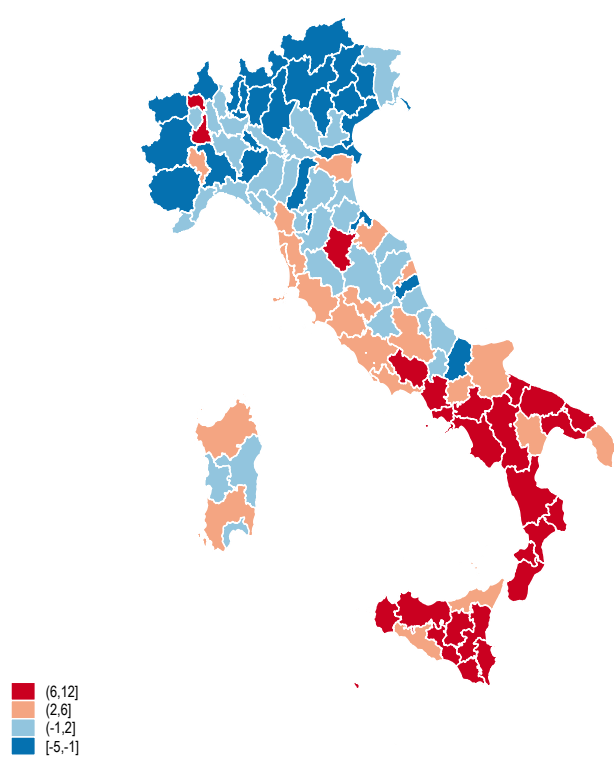

Notes: Results from models comparing the Covid cohorts and the Non-Covid cohorts controlling for students' gender, standardized scores in the previous INVALSI test, the ESCS indicator and the interaction between an indicator for being in the Covid cohort and standardized scores in the previous INVALSI test, run separately for each province. The Covid cohort identifies students for whom the achievement outcome in grade 5 or grade 8 was measured in $2020-2021$. Scores in the previous INVALSI test are standardized to have a mean of zero and a standard deviation of one in their respective grades and cohorts. Results are presented with $95 \%$ confidence intervals obtained by clustering students within classrooms they attended in the year where outcomes are measured.

Source: INVALSI 2015-2016, 2017-2018, 2018-2019 and 2020-2021 (grades 2, 5, 8).

\section{Heterogeneity by SES and gender}

Results presented in Figure 4 and Figure 5 indicate that the pandemic reduced SES differentials in math achievement, especially among higher achieving students. Among grade 5 students, there were no SES differentials in the impact of being in the Covid cohort for students who had low levels of previous achievement. Among the highest-achievers (2 SD above the mean) the pandemic was associated with an improvement of 13 points for children in the lowest quartile of the ESCS distribution and an improvement of 7 points among children in the highest quartile. Similarly, among grade 8 students, there were no SES differentials in the impact of being in the Covid cohort among students who had obtained very low levels of achievement in grade 5 . However, among the highest-achievers (2 SD above the mean), the pandemic was associated with an improvement of 5 points among children in the lowest quartile of the ESCS distribution, but a decline of 1 point among children in the highest quartile. Results are similar when using parental educational attainment instead of the ESCS indicator (Figure A7 and Figure A8 in the Appendix). 
The overall effect of the pandemic on SES disparities however depends on the relative number of advantaged and disadvantaged students among the high achieving and the low achieving groups, since irrespective of SES condition the pandemic had greater negative effects on low achievers. Figure 4 and Figure 5 illustrate that low SES students were more likely to have had lower levels of achievement before the pandemic than high SES students. As such, on average, the effect of the pandemic was that it increased disparities between the most disadvantaged and other students at grade 8 when not considering prior achievement. After prior achievement is controlled for, the pandemic slightly reduced SES disparities (Table A3 in the Appendix).

Figure 4: The impact of being in the Covid cohort and previous math scores on math achievement in grade 5 , by SES

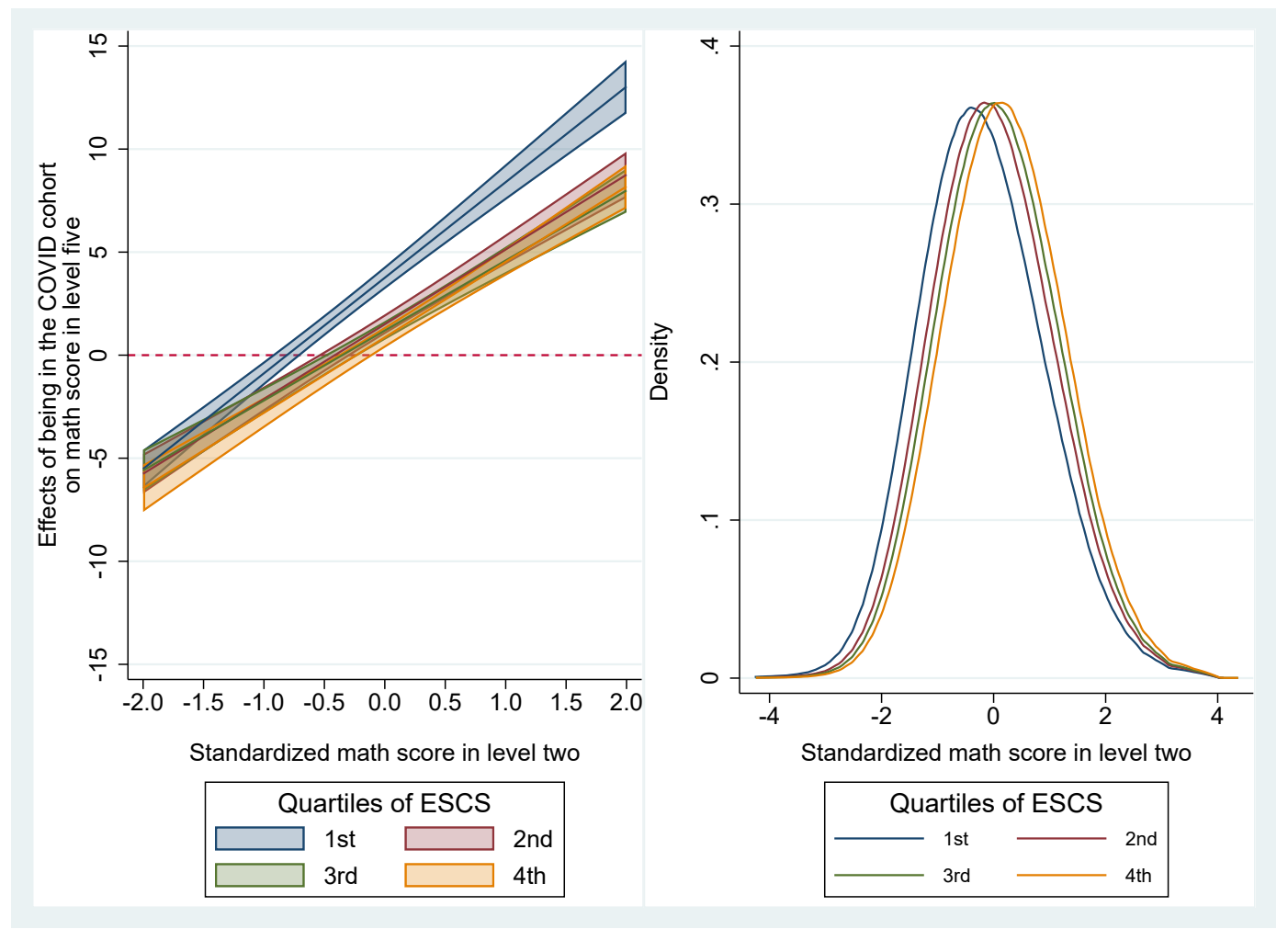

Notes:Results from models comparing the Covid cohorts and the Non-Covid cohorts controlling for students' gender, standardized scores in the previous INVALSI test, the ESCS indicator, province fixed effects, as well as the interaction between an indicator for being in the Covid cohort, standardized scores in the previous INVALSI test and the ESCS indicator. The Covid cohort identifies students for whom the achievement outcome in grade 5 or grade 8 was measured in 2020-2021. Scores in the previous INVALSI test are standardized to have a mean of zero and a standard deviation of one in their respective grades and cohorts. Results are presented with $95 \%$ confidence intervals obtained by clustering students within classrooms they attended in the year where outcomes are measured.

Source: INVALSI 2015-2016, 2017-2018, 2018-2019 and 2020-2021 (grades 2, 5, 8). 
Figure 5: The impact of being in the Covid cohort and previous math scores on math achievement in grade 8 , by SES

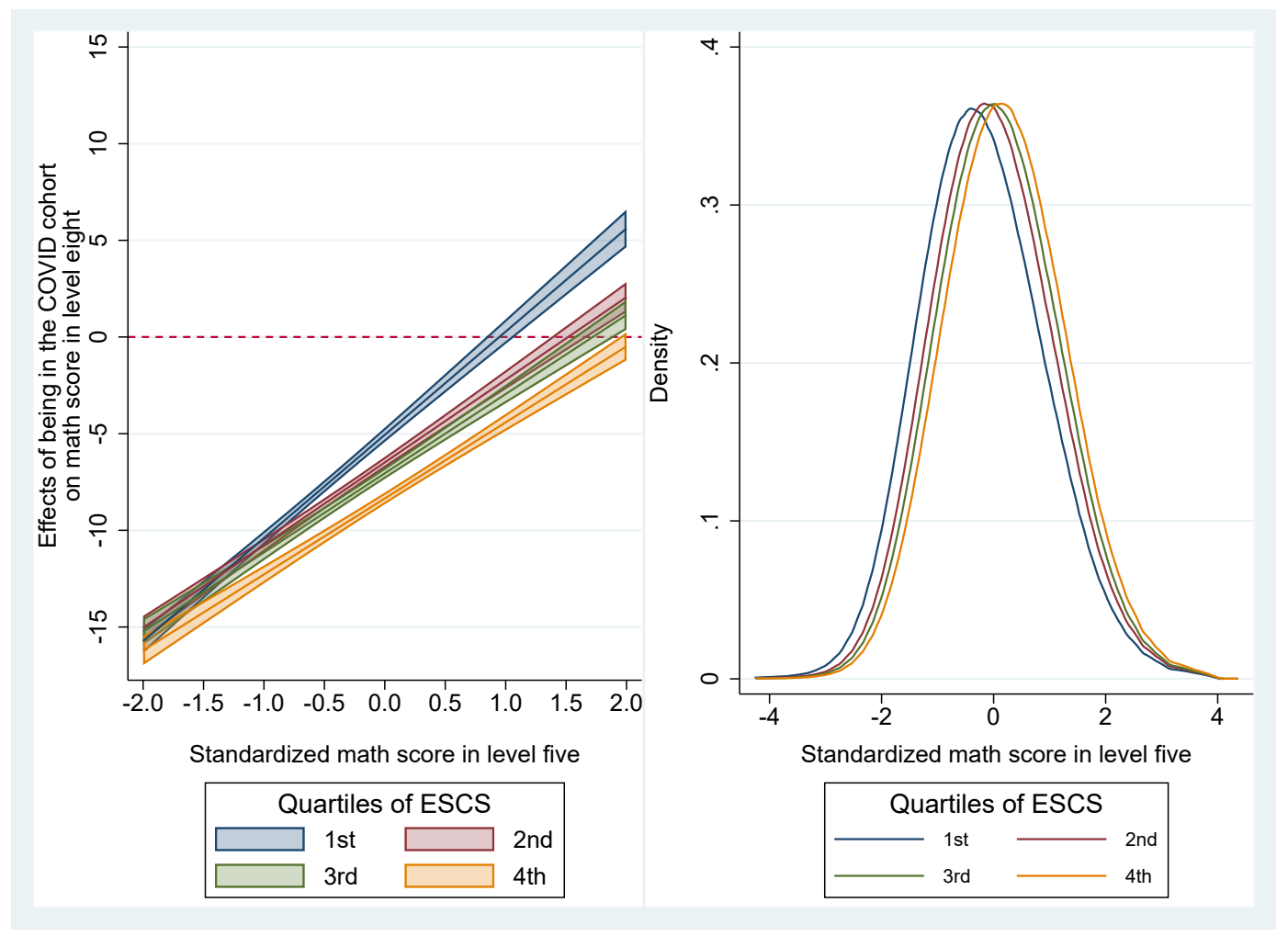

\begin{abstract}
Notes: Results from models comparing the Covid cohorts and the Non-Covid cohorts controlling for students' gender, standardized scores in the previous INVALSI test, the ESCS indicator, province fixed effects, as well as the interaction between an indicator for being in the Covid cohort, standardized scores in the previous INVALSI test and the ESCS indicator. The Covid cohort identifies students for whom the achievement outcome in grade 5 or grade 8 was measured in 2020-2021. Scores in the previous INVALSI test are standardized to have a mean of zero and a standard deviation of one in their respective grades and cohorts. Results are presented with $95 \%$ confidence intervals obtained by clustering students within classrooms they attended in the year where outcomes are measured.

Source: INVALSI 2015-2016, 2017-2018, 2018-2019 and 2020-2021 (grades 2, 5, 8).
\end{abstract}

When considering the impact of school disruptions on gender inequalities in math achievement, we see a reduction in gender gaps in grade 8 and an almost null effect in grade 5 (See Figure A5 in the Appendix). In grade 8, we also identify that gender differences in the effects of the pandemic on mathematics achievement differed depending on initial levels of math achievement, with less negative effects among high achieving girls (Figure 7). For example, in grade 8, girls in the Covid cohort who had levels of mathematics achievement in grade 5 that were $1 \mathrm{SD}$ above the mean had similar levels of mathematics achievement as similar girls in the Non-Covid cohort. However, boys in the Covid cohort who had levels of mathematics achievement in grade 5 that were 1 SD above the mean had 4 points lower scores in mathematics than similar boys in the Non-Covid cohort. Even though gender differences in the effect of the pandemic were especially pronounced among highest achievers, the pandemic narrowed the gender gap in math achievement across the entire performance distribution in grade 8 . In grade 5, gender differences in the impact of being in the Covid cohort were null throughout the distribution of previous achievement (Figure 6). 
Figure 6: The impact of being in the Covid cohort and previous math scores on math achievement in grade 5 , by gender

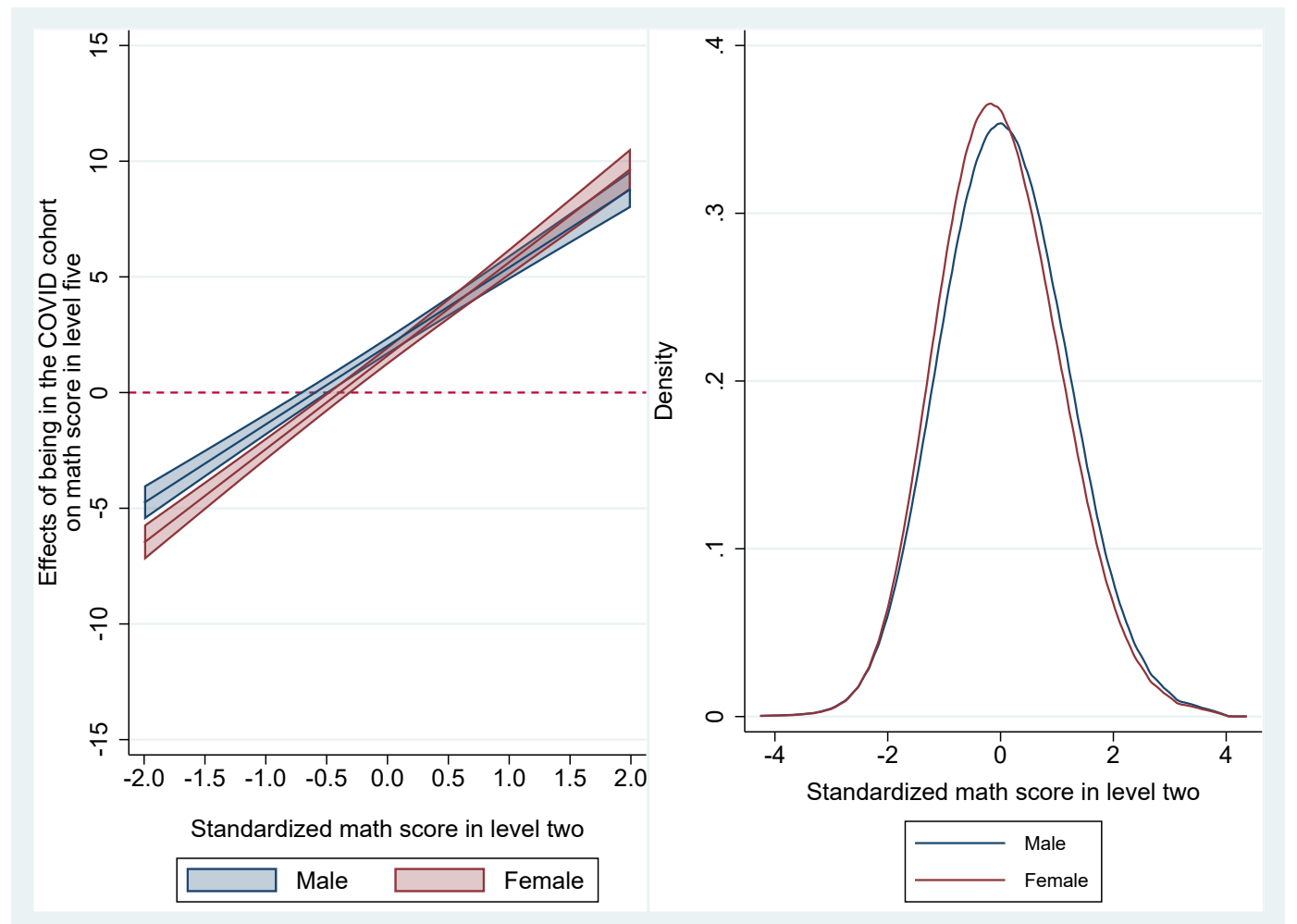

Notes: Results from models comparing the Covid cohorts and the Non-Covid cohorts controlling for students' gender, standardized scores in the previous INVALSI test, the ESCS indicator, province fixed effects, as well as the interaction between an indicator for being in the Covid cohort, standardized scores in the previous INVALSI test and students' gender. The Covid cohort identifies students for whom the achievement outcome in grade 5 or grade 8 was measured in 2020-2021. Scores in the previous INVALSI test are standardized to have a mean of zero and a standard deviation of one in their respective grades and cohorts. Results are presented with $95 \%$ confidence intervals obtained by clustering students within classrooms they attended in the year where outcomes are measured.

Source: INVALSI 2015-2016, 2017-2018, 2018-2019 and 2020-2021 (grades 2, 5, 8). 
Figure 7: The impact of being in the Covid cohort and previous math scores on math achievement in grade 8 , by gender

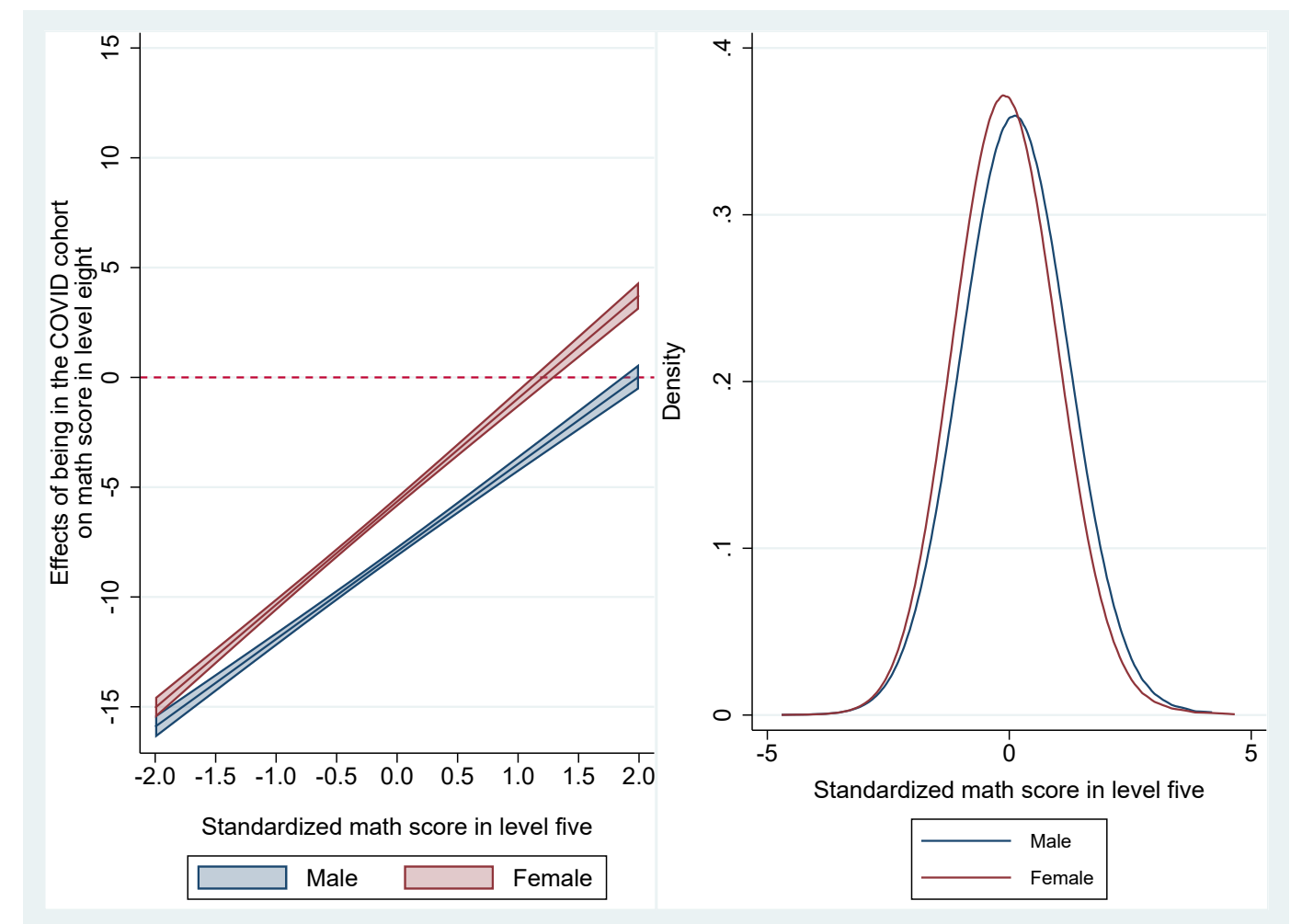

Notes: Results from models comparing the Covid cohorts and the Non-Covid cohorts controlling for students' gender, standardized scores in the previous INVALSI test, the ESCS indicator, province fixed effects, as well as the interaction between an indicator for being in the Covid cohort, standardized scores in the previous INVALSI test and students' gender. The Covid cohort identifies students for whom the achievement outcome in grade 5 or grade 8 was measured in 2020-2021. Scores in the previous INVALSI test are standardized to have a mean of zero and a standard deviation of one in their respective grades and cohorts. Results are presented with $95 \%$ confidence intervals obtained by clustering students within classrooms they attended in the year where outcomes are measured.

Source: INVALSI 2015-2016, 2017-2018, 2018-2019 and 2020-2021 (grades 2, 5, 8).

\section{Reading scores}

Results presented in Figure 8 illustrate the impact of the pandemic on reading achievement among students in grades 5 and 8 (for coefficients see Table A2, Figure A9 and Figure A10 in the Appendix). Figure 8 indicates that, on average, students in the grade 5 Covid cohort experienced a small improvement (2 points) in reading achievement compared to the NonCovid cohort, while those in grade 8 had a lower achievement (3 points). The figure also shows that the improvement in grade 5 was concentrated among students whose prior achievement was at or below the average. By contrast, in the grade 8 Covid cohort, students performing at or below the average experienced a reduction in reading achievement, while students with very high-achievement before the pandemic (2 SD above the mean) had similar scores as those obtained by students in the Non-Covid cohort. These results indicate that school disruptions reduced inequalities by level of previous reading achievement among students in grade 5 , but amplified them among students in grade 8. 
Figure 8: The impact of being in the Covid cohort and previous reading scores on reading achievement

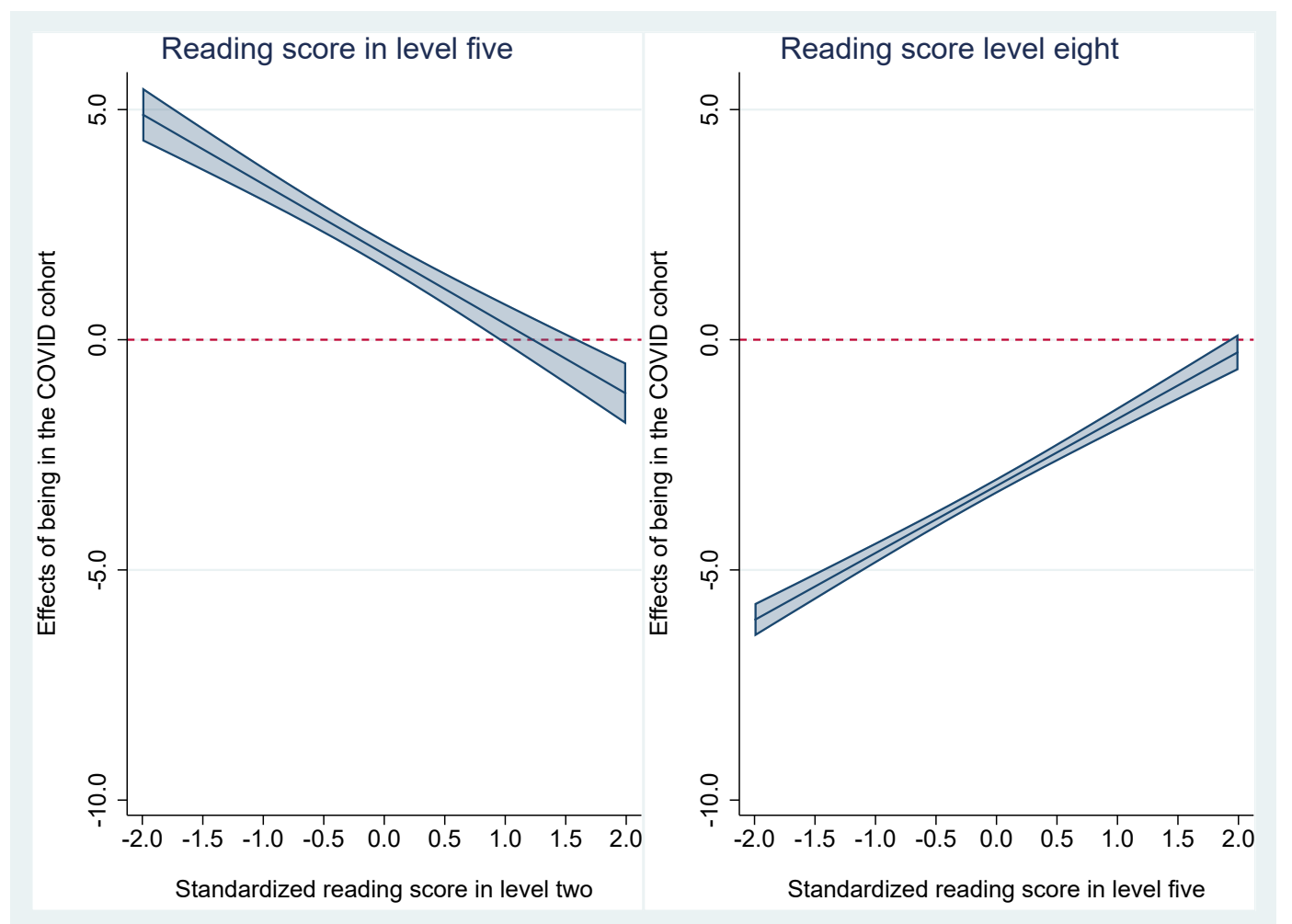

\begin{abstract}
Notes: Results from models comparing the Covid cohorts and the Non-Covid cohorts controlling for students' gender, standardized scores in the previous INVALSI test, the ESCS indicator, province fixed effects and the interaction between an indicator for being in the Covid cohort and standardized scores in the previous INVALSI test. The Covid cohort identifies students for whom the achievement outcome in grade 5 or grade 8 was measured in 2020-2021. Scores in the previous INVALSI test are standardized to have a mean of zero and a standard deviation of one in their respective grades and cohorts. Results are presented with $95 \%$ confidence intervals obtained by clustering students within classrooms they attended in the year where outcomes are measured.

Source: INVALSI 2015-2016, 2017-2018, 2018-2019 and 2020-2021 (grades 2, 5, 8).
\end{abstract}

Similarly to results for math, Figure 9 shows that the positive effects of being in the Covid cohort were mostly recorded in South and Central Italy, although the results are less marked than those presented for mathematics, i.e. within macro-regions there is greater variability in the effects of the pandemic on average levels of achievement. These findings suggest that the pandemic may have reduced reading achievement inequalities between Southern and Northern provinces since, in general, levels of achievement are lower in the South than in the North. However, Figure 10 shows that, within-provinces, the pandemic may have magnified achievement disparities in Southern provinces but reduced achievement disparities in Northern ones, especially for students who were in the grade 8 Covid cohort. This is because in provinces in the South the pandemic had an especially positive effect on the highest achieving students while in the North, those who suffered the most negative outcomes compared to students with similar characteristics but who sat the INVALSI test before the pandemic. 
Figure 9: The impact of being in the Covid cohort on reading achievement
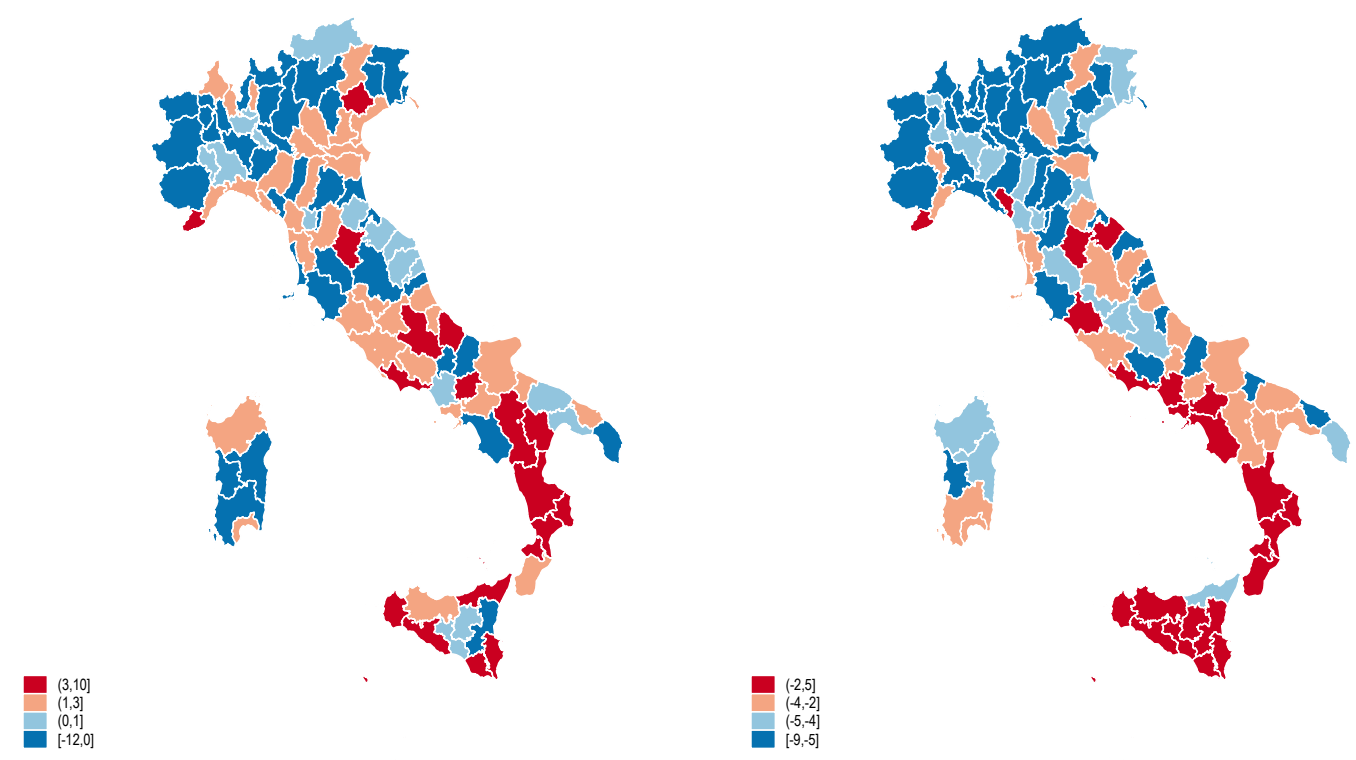

Notes: Results from models comparing the Covid cohorts and the Non-Covid cohorts controlling for students' gender, standardized scores in the previous INVALSI test, and the ESCS indicator, run separately for each province. The Covid cohort identifies students for whom the achievement outcome in grade 5 or grade 8 was measured in 2020-2021. Scores in the previous INVALSI test are standardized to have a mean of zero and a standard deviation of one in their respective grades and cohorts.

Source: INVALSI 2015-2016, 2017-2018, 2018-2019 and 2020-2021 (grades 2, 5, 8). 
Figure 10: The impact of being in the Covid cohort and previous reading scores on reading achievement, by province

Covid cohort * previous performance and 5th grade reading results

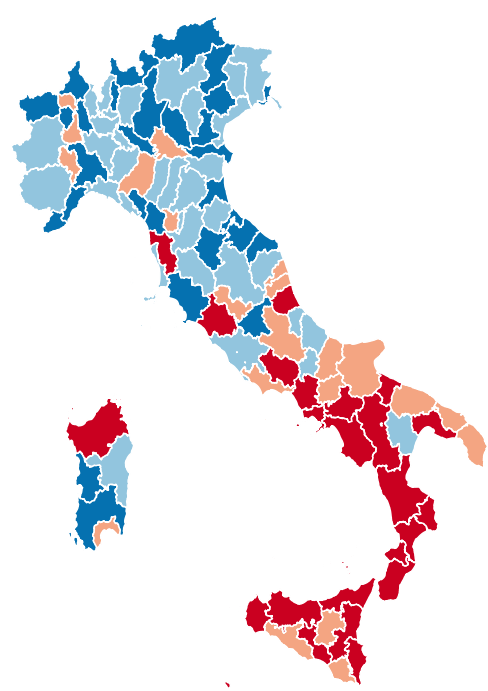

Covid cohort * previous performance and 8th grade reading results

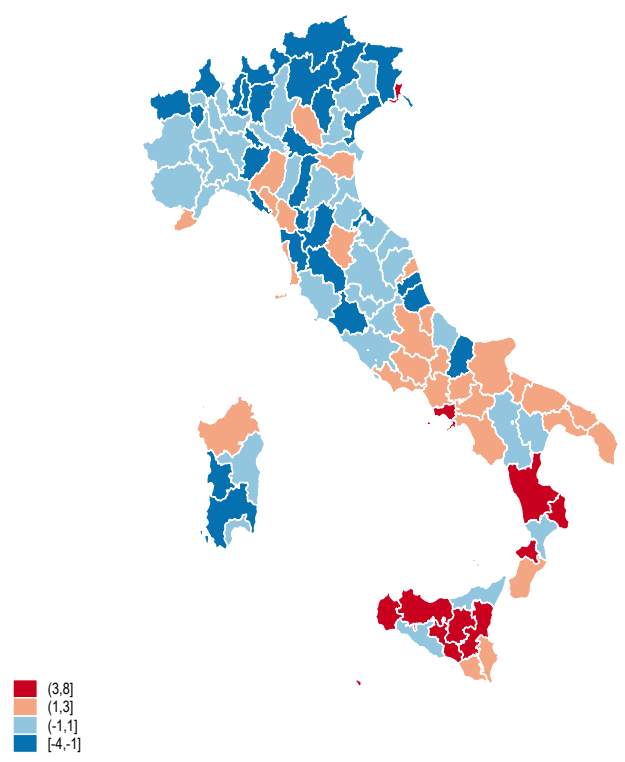

Notes: Results from models comparing the Covid cohorts and the Non-Covid cohorts controlling for students' gender, standardized scores in the previous INVALSI test, the ESCS indicator and the interaction between an indicator for being in the Covid cohort and standardized scores in the previous INVALSI test, run separately for each province. The Covid cohort identifies students for whom the achievement outcome in grade 5 or grade 8 was measured in $2020-2021$. Scores in the previous INVALSI test are standardized to have a mean of zero and a standard deviation of one in their respective grades and cohorts. Results are presented with $95 \%$ confidence intervals obtained by clustering students within classrooms they attended in the year where outcomes are measured.

Source: INVALSI 2015-2016, 2017-2018, 2018-2019 and 2020-2021 (grades 2, 5, 8).

\section{Heterogeneity by SES and gender}

Results presented in Figure 11 indicate that the pandemic reduced SES differentials in reading achievement among grade 5 students with similar levels of prior achievement: the improvement in reading achievement was largest for low-SES students (in the 1st quartile of ESCS distribution) whose previous achievement was in the middle of the distribution. Results are comparable to those obtained by using parental educational attainment instead of the ESCS indicator (Figure A16in the Appendix). The overall impact of pandemic-related disruptions on SES differentials in reading achievement is also documented in Figure A11 in the Appendix. Figure 12 shows that among grade 8 students, SES differentials were not significantly impacted by pandemic-realted disruptions (see also Figure A11 in the Appendix). 
Figure 11: The impact of being in the Covid cohort and previous reading scores on reading achievement in grade 5 , by SES

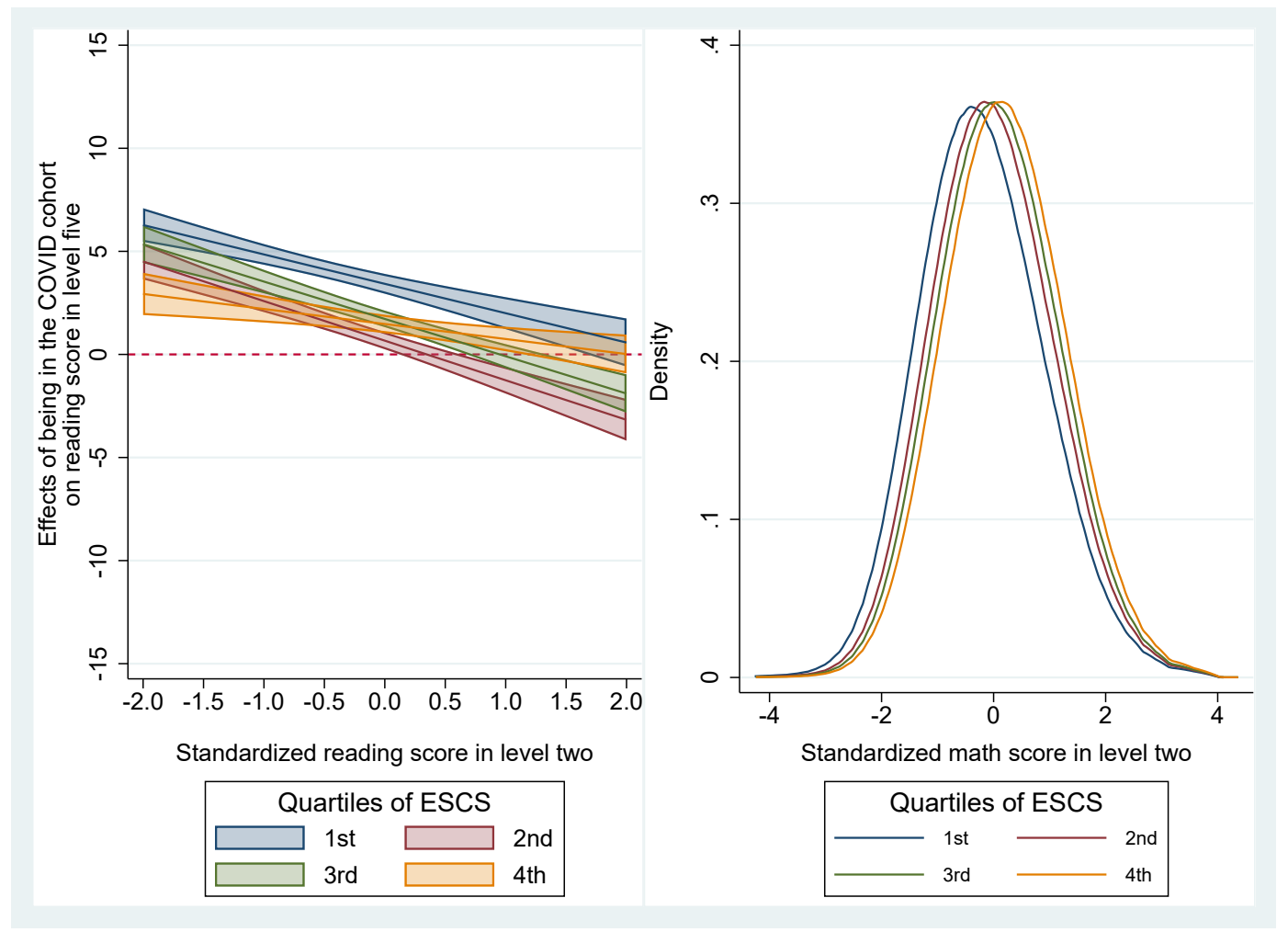

Notes:Results from models comparing the Covid cohorts and the Non-Covid cohorts controlling for students' gender, standardized scores in the previous INVALSI test, the ESCS indicator, province fixed effects, as well as the interaction between an indicator for being in the Covid cohort, standardized scores in the previous INVALSI test and the ESCS indicator. The Covid cohort identifies students for whom the achievement outcome in grade 5 or grade 8 was measured in 2020-2021. Scores in the previous INVALSI test are standardized to have a mean of zero and a standard deviation of one in their respective grades and cohorts. Results are presented with $95 \%$ confidence intervals obtained by clustering students within classrooms they attended in the year where outcomes are measured.

Source: INVALSI 2015-2016, 2017-2018, 2018-2019 and 2020-2021 (grades 2, 5, 8). 
Figure 12: The impact of being in the Covid cohort and previous reading scores on reading achievement in grade 8 , by SES

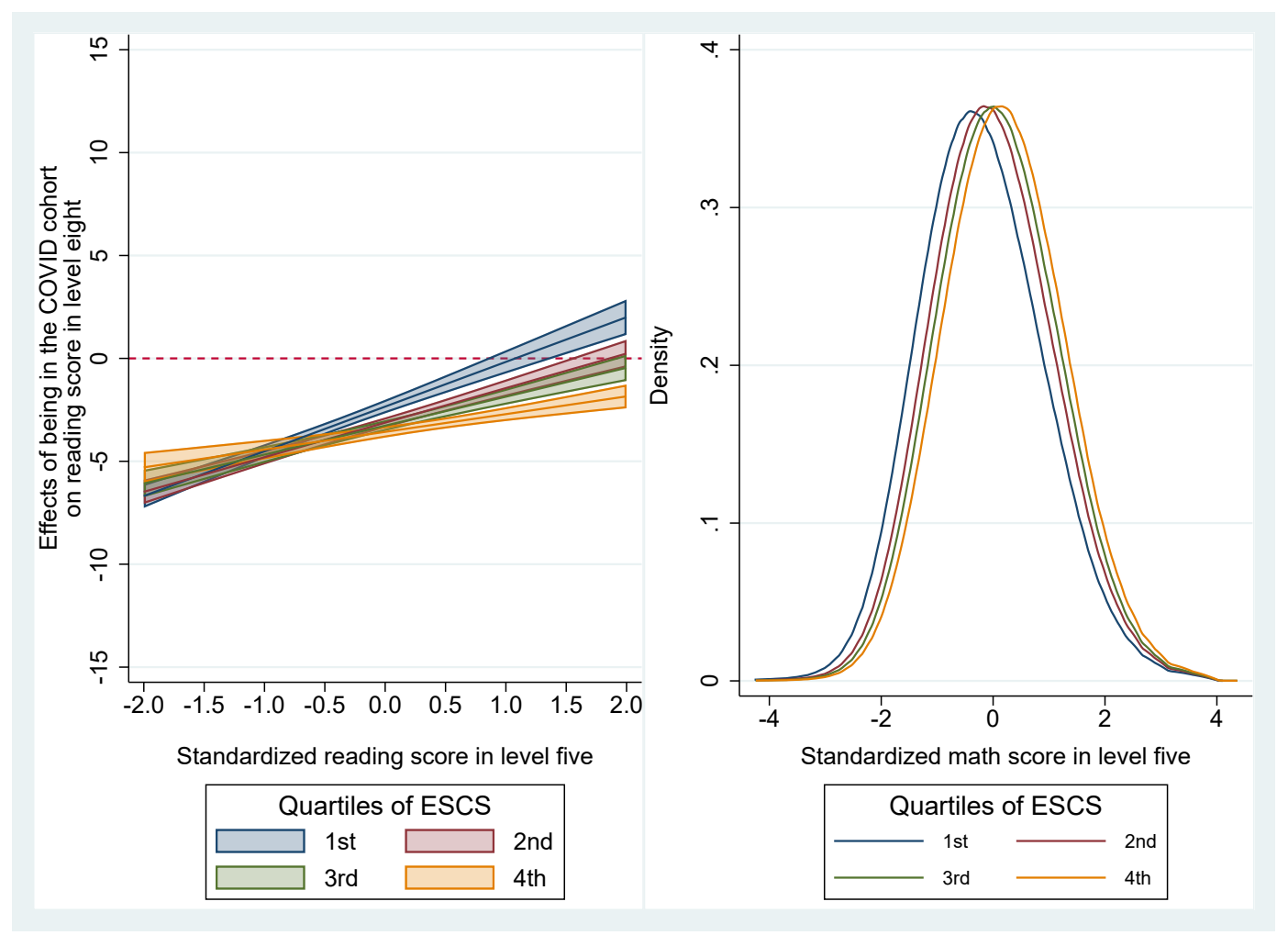

\begin{abstract}
Notes: Results from models comparing the Covid cohorts and the Non-Covid cohorts controlling for students' gender, standardized scores in the previous INVALSI test, the ESCS indicator, province fixed effects, as well as the interaction between an indicator for being in the Covid cohort, standardized scores in the previous INVALSI test and the ESCS indicator. The Covid cohort identifies students for whom the achievement outcome in grade 5 or grade 8 was measured in 2020-2021. Scores in the previous INVALSI test are standardized to have a mean of zero and a standard deviation of one in their respective grades and cohorts. Results are presented with $95 \%$ confidence intervals obtained by clustering students within classrooms they attended in the year where outcomes are measured.

Source: INVALSI 2015-2016, 2017-2018, 2018-2019 and 2020-2021 (grades 2, 5, 8).
\end{abstract}

In terms of gender, the improvement in reading achievement in grade 5 was mostly recorded among male students and especially among low achievers (Figure 13). Among very low achievers (2 SD below the average) in the Covid cohort, male students experienced an improvement in reading achievement of about 6 points, while female students had an improvement of about 3 points. Among grade 8 students, boys experienced a lower drop in reading achievement as a result of the pandemic, and the gap compared to female students was the same throughout the distribution of previous academic achievement (Figure 14). 
Figure 13: The impact of being in the Covid cohort and previous reading scores on reading achievement in grade 5 , by gender

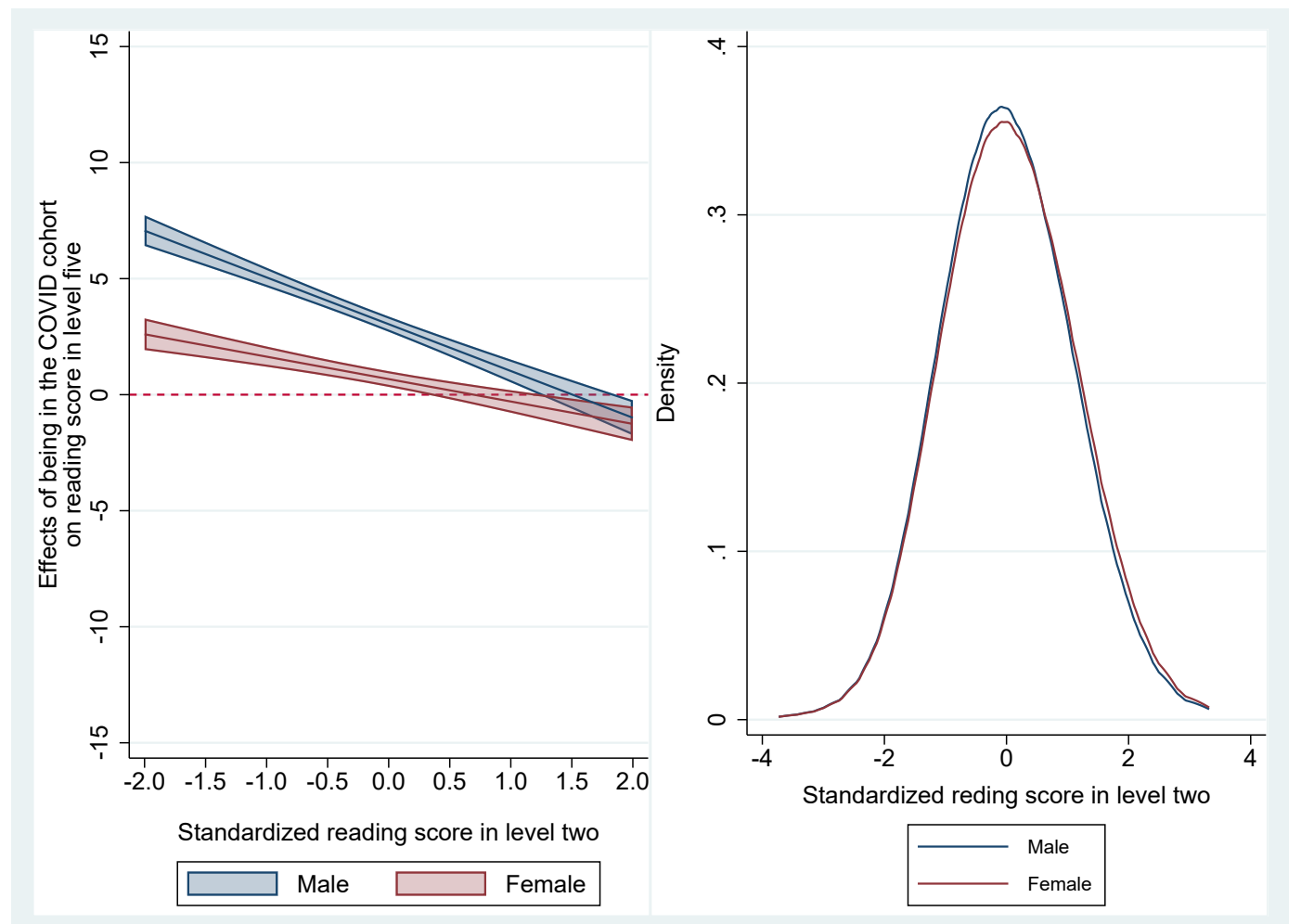

Notes: Results from models comparing the Covid cohorts and the Non-Covid cohorts controlling for students' gender, standardized scores in the previous INVALSI test, the ESCS indicator, province fixed effects, as well as the interaction between an indicator for being in the Covid cohort, standardized scores in the previous INVALSI test and students' gender. The Covid cohort identifies students for whom the achievement outcome in grade 5 or grade 8 was measured in 2020-2021. Scores in the previous INVALSI test are standardized to have a mean of zero and a standard deviation of one in their respective grades and cohorts. Results are presented with $95 \%$ confidence intervals obtained by clustering students within classrooms they attended in the year where outcomes are measured.

Source: INVALSI 2015-2016, 2017-2018, 2018-2019 and 2020-2021 (grades 2, 5, 8). 
Figure 14: The impact of being in the Covid cohort and previous reading scores on reading achievement in grade 8 , by gender

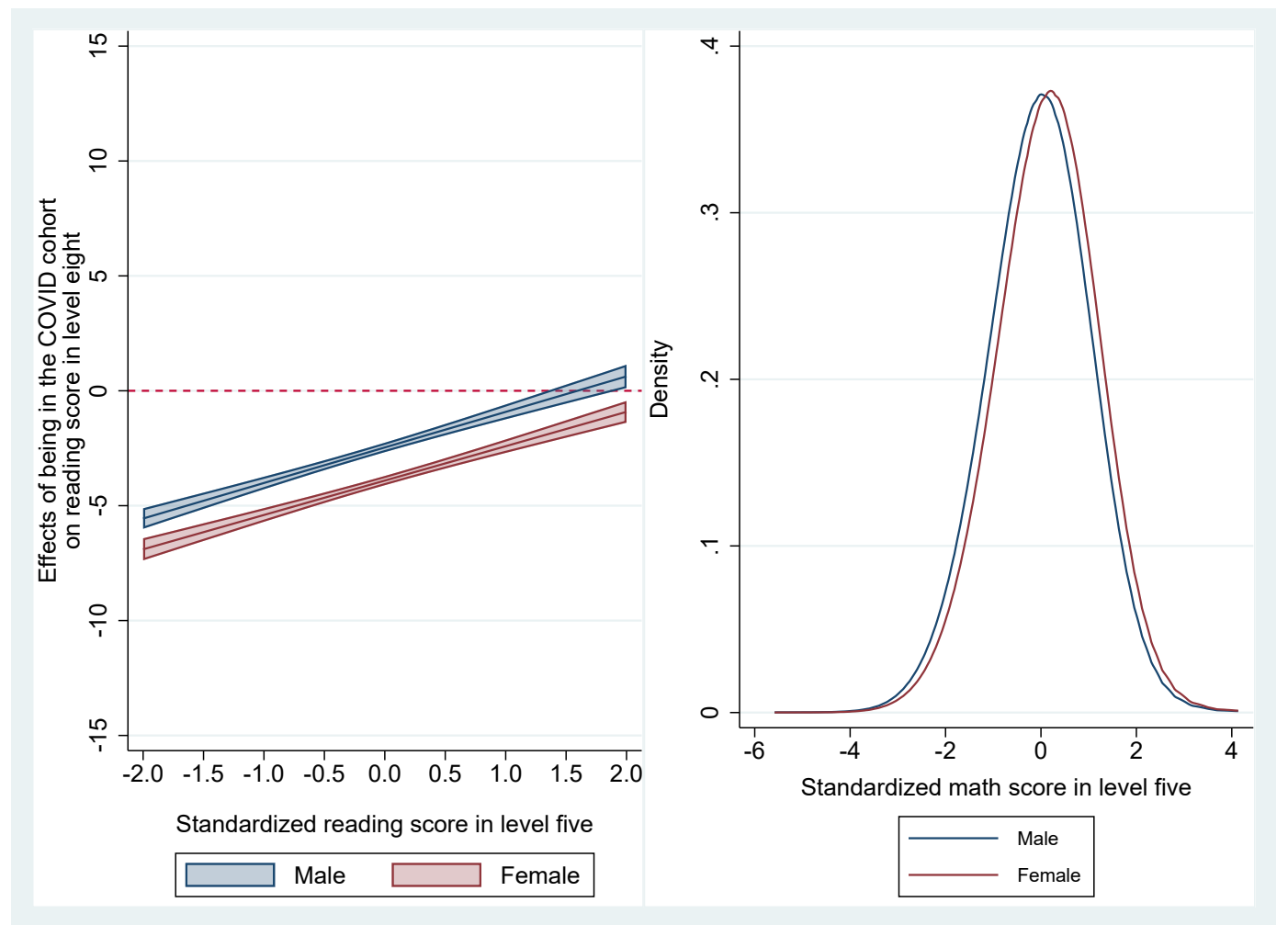

Notes: Results from models comparing the Covid cohorts and the Non-Covid cohorts controlling for students' gender, standardized scores in the previous INVALSI test, the ESCS indicator, province fixed effects, as well as the interaction between an indicator for being in the Covid cohort, standardized scores in the previous INVALSI test and students' gender. The Covid cohort identifies students for whom the achievement outcome in grade 5 or grade 8 was measured in 2020-2021. Scores in the previous INVALSI test are standardized to have a mean of zero and a standard deviation of one in their respective grades and cohorts. Results are presented with $95 \%$ confidence intervals obtained by clustering students within classrooms they attended in the year where outcomes are measured.

Source: INVALSI 2015-2016, 2017-2018, 2018-2019 and 2020-2021 (grades 2, 5, 8).

\section{Conclusions and Discussion}

The aim of the present study was to provide a comprehensive assessment of the effects of pandemic-related disruptions on the mathematics and reading achievement of students who completed primary school and lower-secondary school in the summer of 2021 in Italy. Estimated results reflect the change in achievement resulting from generalised and localised school closures, as well as the changes in the life of children and their families that resulted from the range of measures that were adopted to limit the spread of the Sars-Cov-2 virus. On the one hand results allow to identify which groups were most negatively hit by educational disruptions. On the other hand, they reveal for which groups the schooling experience before the pandemic hit was most conducive to learning. Results reveal a very heterogeneous picture.

First, on average, the pandemic appears to have had a negative effect on older children who completed lower-secondary school but not necessarily on younger children who completed primary school. In fact, we estimate that, on average, the grade 5 Covid cohort experienced a small increase in both math and reading achievement compared to the grade 5 Non-Covid cohort. Previous studies highlighted a stronger negative effects of the pandemic on the achievement 
of younger children (Tomasik et al., 2021). Differences between such studies and our results could be due to the fact that previous studies estimated the effects of the first wave of the pandemic while we study longer-term effects. In the first wave, schools catering to students of all ages closed and younger children and their schools may have been especially ill equipped to move instruction online. By contrast, after the summer of 2020, primary schools in Italy generally remained open more than lower and upper secondary schools, thereby pandemic-related disruptions were less pronounced among younger children.

Second, in mathematics we find that the pandemic had a more negative effect the lower the level of previous achievement of students (as indicated by the grade 2 INVALSI test for the grade 5 cohorts and the grade 5 INVALSI test for the grade 8 cohort) and a less negative or even positive effect among students with the highest level of previous achievement. Third, in reading we find the same pattern observed in mathematics among grade 8 students but among grade 5 students the pandemic appears to have benefited the most those students who had the lowest levels of baseline achievement.

Fourth, we find that the overall greater negative effect of the pandemic on socio-economically disadvantaged students in grade 5 and grade 8 in mathematics is due to the fact that they had, on average, lower levels of achievement before the pandemic hit. In fact, among students with equal levels of prior achievement, the pandemic did not widen, and in certain cases reduced, socio-economic differentials. In grade 8 (mathematics and reading) and in grade 5 (mathematics) the pandemic had a positive effect on high achieving but low SES students - those who are referred to as academically resilient in the literature. For example, while there were no SES differentials in the impact of being in the Covid-cohort among the lowest achieving grade 8 students in mathematics, among the highest achievers (2SD above the mean), the pandemic was associated with an improvement of 5 points among children in the lowest quartile of the ESCS distribution, but a decline of 1 point among children in the highest quartile.

This result could reflect very different mechanisms. It could reflect the unobserved skills and motivation that high-achieving but socio-economically disadvantaged children possess. It could also reflect that students who are used to overcome challenges had built protective factors that helped them be resilient during the pandemic. However it could also reflect the fact that distance learning might have reduced some of the hidden stereotypes and biases that may guide teachers' behaviours during regular face to face instruction. Finally, distance learning might have also reduced negative peer influences that these students might experience during regular schooling (including being the victims of bullying or simply low-levels of educational expectations). These results are not aligned with the simulated effects of Covid on skills acquisition (Agostinelli et al., 2022) and therefore warrant further analyses and investigation.

Fifth, the pandemic also appears to have reduced gender disparities. In reading, the positive effect of the pandemic was most pronounced among the lowest achieving boys. In mathematics, among grade 8 students, the pandemic benefited the highest achieving girls. In particular, results on gender differences in mathematics are in line with those observed for socio-economic status: the pandemic appears to have led to improvements among the group who, before the pandemic, was under-represented among the highest achievers. Also in line 
with results on socio-economic condition, the result of a positive effect of the pandemic on the highest achieving girls in mathematics could reflect a variety of mechanisms. It could reflect the unobserved skills and motivation that high-achieving girls possess or their willingness and ability to defeat expectations. Alternatively, educational disruptions due to the pandemic might have disrupted the influence of any stereotypes teachers and peers might have held on the math ability of girls.

Sixth, students who sat the INVALSI test in 2021 in many provinces in the South achieved at a higher level or only at marginally lower levels than similar students in the same provinces who had sat the INVALSI test before the pandemic hit in 2019. By contrast, students who sat the INVALSI test 2021 in many provinces in the North achieved at a significantly lower level than similar students in the same provinces who had sat the INVALSI test before the pandemic hit in 2019. At the national level, the pandemic acted as an equalising force: it generally reduced to a larger degree the achievement of students living in areas of the country that had higher levels of achievement before the pandemic. However, at the local level the pandemic led to increases in achievement disparities. In the South the positive effects (or less negative effects) were generally more concentrated among the highest achievers. By contrast the pandemic led to reductions in achievement disparities in the North because the positive effects (or less negative effects) were generally more concentrated among the lowest achievers.

Our work examined the outcomes of children in primary and lower-secondary school for two reasons. First, in Italy grade retention is a common phenomenon among upper secondary school students so longitudinal analyses of older children might yield biased estimates if grade retention policies differed before and after Covid-19. Second, by focusing on children who have not yet completed their compulsory studies, we aim to provide information to education policy makers and educators so that interventions can be put in place to reduce the immediate negative effects of the pandemic for these children but also improve schooling to make it more equitable in the longer term. Evidence from the INVALSI national report (INVALSI, 2022) suggests that children in upper secondary school experienced a considerably greater negative effect because of the pandemic and future studies should consider this crucial group.

The current study is descriptive: as such it can be used to identify what effects the pandemic had, but not why. For example, we do not have information on how children spent their time before the pandemic hit, when schools were closed and when mobility was restricted by law. Nor do we have information on the level of engagement of their parents, what activities teachers and school principals put in place to guarantee the provision of educational services during the pandemic and the peer environment students experienced before and during the pandemic. The pandemic not only disrupted how teaching and learning were organized but first and foremost the social environments in which students operated. As such, it might have modified the social norms and expectations students held for themselves but also the social norms they confronted from peers, teachers and parents. Finally, the study presents geographical variation in effects but in the absence of detailed information at the provincial level on the length of school closures, it is impossible to assess if estimates reflect underlying differences across provinces, school closures or other effects of the pandemic. Further research 
is needed to better identify the mechanisms responsible for observed effects. 


\section{References}

Adams-Prassl, A., Boneva, T., Golin, M., and Rauh, C. (2020). Inequality in the impact of the coronavirus shock: Evidence from real time surveys. Journal of Public Economics, 189:104245.

Agasisti, T., Avvisati, F., Borgonovi, F., and Longobardi, S. (2018). Academic resilience: What schools and countries do to help disadvantaged students succeed in PISA. OECD Education Working Papers 167.

Agasisti, T., Avvisati, F., Borgonovi, F., and Longobardi, S. (2021). What School Factors are Associated with the Success of Socio-Economically Disadvantaged Students? An Empirical Investigation Using PISA Data. Social Indicators Research, 157(2):749-781.

Agostinelli, F., Doepke, M., Sorrenti, G., and Zilibotti, F. (2022). When the great equalizer shuts down: Schools, peers, and parents in pandemic times. Journal of Public Economics, 206:104574.

Andrew, A., Sevilla, A., Phimister, A., Krutikova, S., Kraftman, L., Farquharson, C., Costa Dias, M., and Cattan, S. (2020). Learning during the lockdown: Real-time data on children's experiences during home learning. Technical report.

Avvisati, F. and Givord, P. (2021). How Much Do 15-Year-Olds Learn over One Year of Schooling? An International Comparison Based on PISA. OECD Education Working Papers. OECD Publishing, Paris.

Bayrakdar, S. and Guveli, A. (2020). Inequalities in home learning and schools' provision of distance teaching during school closure of COVID-19 lockdown in the UK. ISER Working Paper Series, No. 2020-09, page 39.

Bhanot $_{*}$, R. T. and Jovanovic, J. (2009). The Links Between Parent Behaviors and Boys' and Girls' Science Achievement Beliefs. Applied Developmental Science, 13(1):42-59.

Bleeker, M. and Jacobs, J. (2004). Achievement in Math and Science: Do Mothers' Beliefs Matter 12 Years Later? Journal of Educational Psychology, 96:97-109.

Bol, T. (2020). Inequality in homeschooling during the Corona crisis in the Netherlands. First results from the LISS Panel. SocArXiv Papers.

Borgonovi, F. and Pokropek, M. (2021). The evolution of the association between ICT use and reading achievement in 28 countries. Computers and Education Open, 2:100047.

Buchmann, C., DiPrete, T. A., and McDaniel, A. (2008). Gender Inequalities in Education. Annual Review of Sociology, 34(1):319-337.

Card, D. and Payne, A. A. (2021). High School Choices and the Gender Gap in Stem. Economic Inquiry, 59(1):9-28. 
Coleman, J. S., Campbell, E. Q., Hobson, C. J., McPartland, J., Mood, A. M., Weinfeld, F. D., and York, R. L. (1966). Equality of Educational Opportunity. National Center for Educational Statistics, Washington D.C.

Conger, R. D. and Donnellan, M. B. (2007). An Interactionist Perspective on the Socioeconomic Context of Human Development. Annual Review of Psychology, 58(1):175-199.

Contini, D., Tommaso, M. L. D., Muratori, C., Piazzalung, D., and Schiavon, L. (2021). The COVID-19 Pandemic and School Closure: Learning Loss in Mathematics in Primary Education. Primary Education, page 32.

Cornwell, C., Mustard, D. B., and Parys, J. V. (2012). Noncognitive Skills and the Gender Disparities in Test Scores and Teacher Assessments. Journal of Human Resources, 48(1):236264.

Covay, E. and Carbonaro, W. (2010). After the Bell: Participation in Extracurricular Activities, Classroom Behavior, and Academic Achievement. Sociology of Education, 83(1):20-45.

Domina, T. (2005). Leveling the Home Advantage: Assessing the Effectiveness of Parental Involvement in Elementary School. Sociology of Education, 78(3):233-249.

Downey, D. B. and Condron, D. J. (2016). Fifty Years since the Coleman Report: Rethinking the Relationship between Schools and Inequality. Sociology of Education, 89(3):207-220.

Downey, D. B., von Hippel, P. T., and Broh, B. A. (2004). Are Schools the Great Equalizer? Cognitive Inequality during the Summer Months and the School Year. American Sociological Review, 69(5):613-635.

Downey, D. B., Yoon, A., and Martin, E. (2018). Schools and Inequality: Implications from Seasonal Comparison Research. Handbooks of Sociology and Social Research. Springer, New York.

Dumais, S. A. (2006). Elementary School Students' Extracurricular Activities: The Effects of Participation on Achievement and Teachers' Evaluations. Sociological Spectrum, 26(2):117147.

Engzell, P., Frey, A., and Verhagen, M. D. (2021). Learning loss due to school closures during the COVID-19 pandemic. Proceedings of the National Academy of Sciences, 118(17):e2022376118.

Flabbi, L. (2012). Gender Differences in Education, Career Choices and Labor Market Outcomes on A Sample of OECD Countries. World Development Report 2012. Gender Equality and Development. World Bank.

Fryer, R. J. and Levitt, S. D. (2009). An Empirical Analysis of the Gender Gap in Mathematics, volume Working Paper 15430 of NBER Working Paper Series. Cambridge, MA. 
Golberstein, E., Wen, H., and Miller, B. F. (2020). Coronavirus Disease 2019 (COVID-19) and Mental Health for Children and Adolescents. JAMA Pediatrics, 174(9):819.

Goldin, C., Katz, L. F., and Kuziemko, I. (1870). The Homecoming of American College Women: The Reversal of the College Gender Gap. page 50.

Grätz, M. and Lipps, O. (2021). Large loss in studying time during the closure of schools in Switzerland in 2020. Research in Social Stratification and Mobility, 71:100554.

Grewenig, E., Lergetporer, P., Werner, K., Woessmann, L., and Zierow, L. (2021). COVID19 and educational inequality: How school closures affect low- and high-achieving students. European Economic Review, 140:103920.

Hammerstein, S., König, C., Dreisörner, T., and Frey, A. (2021). Effects of COVID-19-Related School Closures on Student Achievement-A Systematic Review. Frontiers in Psychology, 12:746289.

INVALSI (2022). I Risultati delle Prove INVALSI 2021. https://www.invalsiopen.it/risultati/risultati-prove-invalsi-2021/.

Jæger, M. M. and Blaabæk, E. H. (2020). Inequality in learning opportunities during Covid-19: Evidence from library takeout. Research in Social Stratification and Mobility, 68:100524.

Jencks, C., Smith, M., Acland, H., Bane, M. J., Cohen, D., Gintis, H., Heyns, B., and Michelson, S. (1972). Inequality: A Reassessment of the Effect of Family and Schooling in America. Basic Books, New York.

Johns Hopkins (2022). Mortality Analyses. https://coronavirus.jhu.edu/data/mortality.

Kuhfeld, M., Soland, J., Tarasawa, B., Johnson, A., Ruzek, E., and Liu, J. (2020). Projecting the Potential Impact of COVID-19 School Closures on Academic Achievement. Educational Researcher, 49(8):549-565.

Lareau, A. (2002). Invisible Inequality: Social Class and Childrearing in Black Families and White Families. American Sociological Review, 67(5):747.

Lareau, A. (2003). Unequal Childhoods: Class, Race, and Family Life. University of California Press, Los Angeles.

Maldonado, J. E. and De Witte, K. (2021). The effect of school closures on standardised student test outcomes. British Educational Research Journal, n/a(n/a).

Marks, G. N., Cresswell, J., and Ainley, J. (2006). Explaining socioeconomic inequalities in student achievement: The role of home and school factors. Educational Research and Evaluation, 12(2):105-128.

Mullis, I. V. S., Martin, M. O., Foy, P., and Hooper, M. (2017). PIRLS 2016 International Results in Reading. TIMSS \& PIRLS International Study Center, Boston, MA. 
Mullis, I. V. S., Martin, M. O., Foy, P., Kelly, D. L., and Fishbein, B. (2020). TIMSS 2019 International Results in Mathematics and Science. TIMSS \& PIRLS International Study Center, Boston, MA.

OECD (2015). The ABC of Gender Equality in Education: Aptitude, Behavior, Confidence. OECD Publishing, Paris.

OECD (2016). PISA 2015 Results (Volume I): Excellence and Equity in Education. OECD Publishing, Paris.

OECD (2021a). Education at a Glance 2021: OECD Indicators. OECD Publishing, Paris.

OECD (2021b). The State of Global Education: 18 Months into the Pandemic. OECD Publishing, Paris.

Passaretta, G. and Skopek, J. (2021). Does Schooling Decrease Socioeconomic Inequality in Early Achievement? A Differential Exposure Approach. American Sociological Review, 86(6):1017-1042.

Reardon, S. F. (2014). The Widening Academic Achievement Gap Between the Rich and the Poor, pages 93-115. Routledge, London.

Robinson-Cimpian, J. P., Lubienski, S. T., Ganley, C. M., and Copur-Gencturk, Y. (2014). Teachers' Perceptions of Students' Mathematics Proficiency May Exacerbate Early Gender Gaps in Achievement. Developmental Psychology, 50(4):1262-1281.

Schaub, M. (2010). Parenting for Cognitive Development from 1950 to 2000: The Institutionalization of Mass Education and the Social Construction of Parenting in the United States. Sociology of Education, 83(1):46-66.

Schult, J., Mahler, N., Fauth, B., and Lindner, M. A. (2021). Did Students Learn Less During the COVID-19 Pandemic? Reading and Mathematics Competencies Before and After the First Pandemic Wave. Preprint, PsyArXiv.

Sirin, S. R. (2005). Socioeconomic Status and Academic Achievement: A Meta-Analytic Review of Research. Review of Educational Research, 75(3):417-453.

Skopek, J. and Passaretta, G. (2021). Socioeconomic Inequality in Children's Achievement from Infancy to Adolescence: The Case of Germany. Social Forces, 100(1):86-112.

Thorn, W. and Vincent-Lancrin, S. (2021). Schooling during a Pandemic: The Experience and Outcomes of Schoolchildren during the First Round of COVID-19 Lockdowns. OECD Publishing, Paris.

Tomasik, M. J., Helbling, L. A., and Moser, U. (2021). Educational gains of in-person vs. distance learning in primary and secondary schools: A natural experiment during the COVID-19 pandemic school closures in Switzerland. International Journal of Psychology, 56(4):566-576. 
von Hippel, P. T., Workman, J., and Downey, D. B. (2018). Inequality in Reading and Math

Skills Forms Mainly before Kindergarten: A Replication, and Partial Correction, of "Are Schools the Great Equalizer?". Sociology of Education, 91(4):323-357.

World Bank, UNESCO, and UNICEF (2021). The State of the Global Education Crisis: A Path to Recovery. The World Bank, UNESCO, and UNICEF, Washington D.C., Paris, New York.

Zaccoletti, S., Camacho, A., Correia, N., Aguiar, C., Mason, L., Alves, R. A., and Daniel, J. R. (2020). Parents' Perceptions of Student Academic Motivation During the COVID-19 Lockdown: A Cross-Country Comparison. Frontiers in Psychology, 11:592670.

\section{Appendix}

Table A1: Description of the Initial and Analytical Covid and Non-Covid Math Achievement Samples

\begin{tabular}{l|c|c|c|c|}
\hline \multirow{2}{*}{ Sample (N) } & \multicolumn{2}{|c|}{ Grade 5 } & \multicolumn{2}{c}{ Grade 8 } \\
& Covid & Non-Covid & Covid & Non-Covid \\
\hline Full & 473,051 & 512,858 & 525,090 & 545,521 \\
\hline Excluding attrition from previous wave & 434,316 & 459,699 & 462,783 & 458,116 \\
\hline Excluding missing outcome & 410,819 & 447,000 & 460,502 & 457,930 \\
\hline Excluding missing previous achievement & 394,879 & 435,741 & 438,764 & 445,149 \\
\hline Excluding missing ESCS & 393,994 & 435,149 & 437,837 & 443,535 \\
\hline Analytical sample & 393,971 & 435,149 & 437,824 & 443,535 \\
\hline Percent of original (\%) & $77(\%)$ & $85(\%)$ & $83(\%)$ & $81(\%)$ \\
\hline \hline
\end{tabular}


Table A2: Predicting grade 5 and grade 8 math and reading achievement

\begin{tabular}{|c|c|c|c|c|}
\hline & \multicolumn{2}{|c|}{ Grade 5} & \multicolumn{2}{|c|}{ Grade 8} \\
\hline & Math & Reading & Math & Reading \\
\hline Score in grade -3 & $\begin{array}{c}16.494^{* * *} \\
(0.126)\end{array}$ & $\begin{array}{c}16.808^{* * *} \\
(0.102)\end{array}$ & $\begin{array}{c}18.702^{* * *} \\
(0.097)\end{array}$ & $\begin{array}{c}20.139^{* * *} \\
(0.076)\end{array}$ \\
\hline COVID cohort & $\begin{array}{c}1.788^{* * *} \\
(0.183)\end{array}$ & $\begin{array}{c}1.864^{* * *} \\
(0.154)\end{array}$ & $\begin{array}{c}-6.787^{* * *} \\
(0.100)\end{array}$ & $\begin{array}{c}-3.176^{* * *} \\
(0.085)\end{array}$ \\
\hline Score in grade $-3 *$ COVID cohort & $\begin{array}{c}3.737^{* * *} \\
(0.160)\end{array}$ & $\begin{array}{c}-1.517^{* * *} \\
(0.141)\end{array}$ & $\begin{array}{c}4.273^{* * *} \\
(0.103)\end{array}$ & $\begin{array}{c}1.456^{* * *} \\
(0.086)\end{array}$ \\
\hline Female student & $\begin{array}{c}-3.634^{* * *} \\
(0.075)\end{array}$ & $\begin{array}{c}6.196^{* * *} \\
(0.073)\end{array}$ & $\begin{array}{c}-0.658^{* * *} \\
(0.070)\end{array}$ & $\begin{array}{c}4.819^{* * *} \\
(0.061)\end{array}$ \\
\hline \multicolumn{5}{|l|}{ ESCS quartile (ref: lowest) } \\
\hline 2nd & $\begin{array}{c}7.427^{* * *} \\
(0.141)\end{array}$ & $\begin{array}{c}7.288^{* * *} \\
(0.128)\end{array}$ & $\begin{array}{c}7.053^{* * *} \\
(0.104)\end{array}$ & $\begin{array}{c}6.336^{* * *} \\
(0.092)\end{array}$ \\
\hline $3 \mathrm{rd}$ & $\begin{array}{c}10.744^{* * *} \\
(0.144)\end{array}$ & $\begin{array}{c}10.978^{* * *} \\
(0.133)\end{array}$ & $\begin{array}{c}11.134^{* * *} \\
(0.112)\end{array}$ & $\begin{array}{c}9.937^{* * *} \\
(0.098)\end{array}$ \\
\hline 4 th & $\begin{array}{c}14.287^{* * *} \\
(0.160)\end{array}$ & $\begin{array}{c}14.920^{* * *} \\
(0.149)\end{array}$ & $\begin{array}{c}17.166^{* * *} \\
(0.126)\end{array}$ & $\begin{array}{c}15.488^{* * *} \\
(0.108)\end{array}$ \\
\hline Constant & $\begin{array}{c}199.616^{* * *} \\
(1.415)\end{array}$ & $\begin{array}{c}187.748^{* * *} \\
\quad(1.437)\end{array}$ & $\begin{array}{c}172.757^{* * *} \\
(0.885)\end{array}$ & $\begin{array}{c}181.203^{* * *} \\
(0.760)\end{array}$ \\
\hline $\begin{array}{l}\text { Observations } \\
R^{2}\end{array}$ & $\begin{array}{c}829120 \\
0.276\end{array}$ & $\begin{array}{c}823190 \\
0.251\end{array}$ & $\begin{array}{c}881359 \\
0.419\end{array}$ & $\begin{array}{c}876385 \\
0.442\end{array}$ \\
\hline
\end{tabular}

Notes: The Covid cohort identifies students for whom the achievement outcome in grade 5 or grade 8 was measured in 2020-2021. Scores in the previous INVALSI test are standardized to have a mean of zero and a standard deviation of one in their respective grades and cohorts. Standard errors obtained from regressions clustering students within classrooms they attended in the year where outcomes are measured. Regression models include province fixed effects. Source: INVALSI 2015-2016, 2017-2018, 2018-2019 and 2020-2021 (grades 2, 5, 8). 
Table A3: Estimating the impact of being in the Covid cohort on math achievement by SES quartile

\begin{tabular}{|c|c|c|c|c|}
\hline & \multicolumn{2}{|c|}{ Grade 5} & \multicolumn{2}{|c|}{ Grade 8} \\
\hline & (1) & (2) & (3) & (4) \\
\hline Female student & $\begin{array}{c}-5.340^{* * *} \\
(0.085)\end{array}$ & $\begin{array}{c}-3.627^{* * *} \\
(0.075)\end{array}$ & $\begin{array}{c}-4.446^{* * *} \\
(0.080)\end{array}$ & $\begin{array}{c}-0.749^{* * *} \\
(0.070)\end{array}$ \\
\hline COVID cohort & $\begin{array}{c}1.705^{* * *} \\
(0.276)\end{array}$ & $\begin{array}{c}2.903^{* * *} \\
(0.271)\end{array}$ & $\begin{array}{c}-7.869^{* * *} \\
(0.177)\end{array}$ & $\begin{array}{c}-6.123^{* * *} \\
(0.177)\end{array}$ \\
\hline \multicolumn{5}{|c|}{ ESCS quartile (ref: lowest) } \\
\hline 2nd & $\begin{array}{c}12.058^{* * *} \\
(0.189)\end{array}$ & $\begin{array}{c}8.075^{* * *} \\
(0.181)\end{array}$ & $\begin{array}{c}11.634^{* * *} \\
(0.155)\end{array}$ & $\begin{array}{c}7.284^{* * *} \\
(0.147)\end{array}$ \\
\hline $3 \mathrm{rd}$ & $\begin{array}{c}16.814^{* * *} \\
(0.192)\end{array}$ & $\begin{array}{c}11.438^{* * *} \\
(0.182)\end{array}$ & $\begin{array}{c}18.094^{* * *} \\
(0.165)\end{array}$ & $\begin{array}{c}11.409^{* * *} \\
(0.157)\end{array}$ \\
\hline 4 th & $\begin{array}{c}22.061^{* * *} \\
(0.205)\end{array}$ & $\begin{array}{c}14.946^{* * *} \\
(0.199)\end{array}$ & $\begin{array}{c}28.024^{* * *} \\
(0.174)\end{array}$ & $\begin{array}{c}17.737^{* * *} \\
(0.172)\end{array}$ \\
\hline \multicolumn{5}{|c|}{ COVID cohort · ESCS quartiles (ref: lowest) } \\
\hline COVID cohort $\cdot$ 2nd & $\begin{array}{c}-1.161^{* * *} \\
(0.299)\end{array}$ & $\begin{array}{c}-1.439^{* * *} \\
(0.281)\end{array}$ & $\begin{array}{c}1.108^{* * *} \\
(0.221)\end{array}$ & $\begin{array}{c}-0.465^{*} \\
(0.200)\end{array}$ \\
\hline COVID cohort $\cdot$ 3rd & $\begin{array}{l}0.500 \\
(0.305)\end{array}$ & $\begin{array}{c}-1.340^{* * *} \\
(0.287)\end{array}$ & $\begin{array}{c}1.966^{* * *} \\
(0.233)\end{array}$ & $\begin{array}{l}-0.470^{*} \\
(0.211)\end{array}$ \\
\hline COVID cohort $\cdot 4$ th & $\begin{array}{c}1.697^{* * *} \\
(0.328)\end{array}$ & $\begin{array}{c}-1.196^{* * *} \\
(0.321)\end{array}$ & $\begin{array}{c}1.868^{* * *} \\
(0.239)\end{array}$ & $\begin{array}{c}-1.005^{* * *} \\
(0.220)\end{array}$ \\
\hline Math score in (level - 3) & & $\begin{array}{c}18.276^{* * *} \\
(0.094)\end{array}$ & & $\begin{array}{c}20.823^{* * *} \\
(0.066)\end{array}$ \\
\hline Constant & $\begin{array}{c}200.946^{* * *} \\
(1.363)\end{array}$ & $\begin{array}{c}198.896^{* * *} \\
(1.427)\end{array}$ & $\begin{array}{c}172.884^{* * *} \\
(0.825)\end{array}$ & $\begin{array}{c}172.270^{* * *} \\
(0.903)\end{array}$ \\
\hline Observations & 856207 & 829120 & 901680 & 881359 \\
\hline$R^{2}$ & 0.062 & 0.274 & 0.156 & 0.416 \\
\hline
\end{tabular}

Notes: The Covid cohort identifies students for whom the achievement outcome in grade 5 or grade 8 was measured in 2020-2021. Scores in the previous INVALSI test are standardized to have a mean of zero and a standard deviation of one in their respective grades and cohorts. Standard errors obtained from regressions clustering students within classrooms they attended in the year where outcomes are measured. Regression models include province fixed effects.

Source: INVALSI 2015-2016, 2017-2018, 2018-2019 and 2020-2021 (grades 2, 5, 8). 
Table A4: Estimating the impact of being in the Covid cohort on reading achievement by SES quartile

\begin{tabular}{|c|c|c|c|c|}
\hline & \multicolumn{2}{|c|}{ Grade 5} & \multicolumn{2}{|c|}{ Grade 8} \\
\hline & $(1)$ & $(2)$ & $(3)$ & (4) \\
\hline Female student & $\begin{array}{c}6.892^{* * *} \\
(0.081)\end{array}$ & $\begin{array}{c}6.175^{* * *} \\
(0.073)\end{array}$ & $\begin{array}{c}8.527^{* * *} \\
(0.074)\end{array}$ & $\begin{array}{c}4.852^{* * *} \\
(0.061)\end{array}$ \\
\hline COVID cohort & $\begin{array}{c}3.686^{* * *} \\
(0.236)\end{array}$ & $\begin{array}{c}3.758^{* * *} \\
(0.230)\end{array}$ & $\begin{array}{c}-3.617^{* * *} \\
(0.166)\end{array}$ & $\begin{array}{c}-2.921^{* * *} \\
(0.153)\end{array}$ \\
\hline \multicolumn{5}{|c|}{ ESCS quartile (ref: lowest) } \\
\hline 2nd & $\begin{array}{c}12.772^{* * *} \\
(0.182)\end{array}$ & $\begin{array}{c}8.745^{* * *} \\
(0.170)\end{array}$ & $\begin{array}{c}12.347^{* * *} \\
(0.152)\end{array}$ & $\begin{array}{c}6.448^{* * *} \\
(0.133)\end{array}$ \\
\hline $3 \mathrm{rd}$ & $\begin{array}{c}17.482^{* * *} \\
(0.188)\end{array}$ & $\begin{array}{c}12.042^{* * *} \\
(0.174)\end{array}$ & $\begin{array}{c}18.847^{* * *} \\
(0.158)\end{array}$ & $\begin{array}{c}10.016^{* * *} \\
(0.139)\end{array}$ \\
\hline 4 th & $\begin{array}{c}23.534^{* * *} \\
(0.195)\end{array}$ & $\begin{array}{c}16.072^{* * *} \\
(0.185)\end{array}$ & $\begin{array}{c}29.047^{* * *} \\
(0.164)\end{array}$ & $\begin{array}{c}15.660^{* * *} \\
(0.149)\end{array}$ \\
\hline \multicolumn{5}{|c|}{ COVID cohort $\cdot$ ESCS quartiles (ref: lowest) } \\
\hline COVID cohort $\cdot$ 2nd & $\begin{array}{c}-3.771^{* * *} \\
(0.265)\end{array}$ & $\begin{array}{c}-3.069^{* * *} \\
(0.251)\end{array}$ & $\begin{array}{c}0.280 \\
(0.208)\end{array}$ & $\begin{array}{l}-0.221 \\
(0.177)\end{array}$ \\
\hline COVID cohort $\cdot 3$ rd & $\begin{array}{c}-1.788^{* * *} \\
(0.274)\end{array}$ & $\begin{array}{c}-2.218^{* * *} \\
(0.257)\end{array}$ & $\begin{array}{c}0.802^{* * *} \\
(0.217)\end{array}$ & $\begin{array}{l}-0.144 \\
(0.185)\end{array}$ \\
\hline COVID cohort $\cdot 4$ th & $\begin{array}{c}-1.448^{* * *} \\
(0.296)\end{array}$ & $\begin{array}{c}-2.435^{* * *} \\
(0.283)\end{array}$ & $\begin{array}{c}0.650^{* *} \\
(0.218)\end{array}$ & $\begin{array}{l}-0.327 \\
(0.189)\end{array}$ \\
\hline Reading score in (level - 3) & & $\begin{array}{c}16.084^{* * *} \\
(0.075)\end{array}$ & & $\begin{array}{c}20.873^{* * *} \\
(0.052)\end{array}$ \\
\hline Constant & $\begin{array}{c}186.018^{* * *} \\
(1.426) \\
\end{array}$ & $\begin{array}{c}186.943^{* * *} \\
(1.437) \\
\end{array}$ & $\begin{array}{c}172.650^{* * *} \\
(0.744) \\
\end{array}$ & $\begin{array}{c}180.996^{* * *} \\
(0.770) \\
\end{array}$ \\
\hline Observations & 842767 & 823190 & 898936 & 876385 \\
\hline$R^{2}$ & 0.072 & 0.251 & 0.141 & 0.442 \\
\hline
\end{tabular}

Notes: The Covid cohort identifies students for whom the achievement outcome in grade 5 or grade 8 was measured in 2020-2021. Scores in the previous INVALSI test are standardized to have a mean of zero and a standard deviation of one in their respective grades and cohorts. Standard errors obtained from regressions clustering students within classrooms they attended in the year where outcomes are measured. Regression models include province fixed effects.

Source: INVALSI 2015-2016, 2017-2018, 2018-2019 and 2020-2021 (grades 2, 5, 8). 
Table A5: Predicting grade 5 and grade 8 math and reading achievement, with SES triple interaction

\begin{tabular}{|c|c|c|c|c|}
\hline & \multicolumn{2}{|c|}{ Grade 5} & \multicolumn{2}{|c|}{ Grade 8} \\
\hline & Math & Reading & Math & Reading \\
\hline Female student & $\begin{array}{c}-3.604^{* * *} \\
(0.075)\end{array}$ & $\begin{array}{c}6.196^{* * *} \\
(0.073)\end{array}$ & $\begin{array}{c}-0.586^{* * *} \\
(0.070)\end{array}$ & $\begin{array}{c}4.819^{* * *} \\
(0.060)\end{array}$ \\
\hline Score in grade - 3 & $\begin{array}{c}14.664^{* * *} \\
(0.178)\end{array}$ & $\begin{array}{c}15.452^{* * *} \\
(0.161)\end{array}$ & $\begin{array}{c}15.488^{* * *} \\
(0.140)\end{array}$ & $\begin{array}{c}18.044^{* * *} \\
(0.125)\end{array}$ \\
\hline COVID cohort & $\begin{array}{c}3.758^{* * *} \\
(0.282)\end{array}$ & $\begin{array}{c}3.427^{* * *} \\
(0.245)\end{array}$ & $\begin{array}{c}-5.532^{* * *} \\
(0.184)\end{array}$ & $\begin{array}{c}-2.494^{* * *} \\
(0.160)\end{array}$ \\
\hline Score in grade $-3 *$ COVID cohort & $\begin{array}{c}4.638^{* * *} \\
(0.251)\end{array}$ & $\begin{array}{c}-1.425^{* * *} \\
(0.226)\end{array}$ & $\begin{array}{c}4.789^{* * *} \\
(0.177)\end{array}$ & $\begin{array}{c}2.018^{* * *} \\
(0.158)\end{array}$ \\
\hline \multicolumn{5}{|l|}{ ESCS quartile (ref: lowest) } \\
\hline 2nd & $\begin{array}{c}8.732^{* * *} \\
(0.184)\end{array}$ & $\begin{array}{c}8.862^{* * *} \\
(0.177)\end{array}$ & $\begin{array}{c}8.419^{* * *} \\
(0.143)\end{array}$ & $\begin{array}{c}7.538^{* * *} \\
(0.131)\end{array}$ \\
\hline $3 \mathrm{rd}$ & $\begin{array}{c}12.134^{* * *} \\
(0.184)\end{array}$ & $\begin{array}{c}12.007^{* * *} \\
(0.180)\end{array}$ & $\begin{array}{c}12.156^{* * *} \\
(0.148)\end{array}$ & $\begin{array}{c}10.718^{* * *} \\
(0.136)\end{array}$ \\
\hline 4 th & $\begin{array}{c}15.808^{* * *} \\
(0.196)\end{array}$ & $\begin{array}{c}16.009^{* * *} \\
(0.189)\end{array}$ & $\begin{array}{c}18.105^{* * *} \\
(0.164)\end{array}$ & $\begin{array}{c}15.980^{* * *} \\
(0.148)\end{array}$ \\
\hline \multicolumn{5}{|c|}{ ESCS quartile ${ }^{*}$ Score in grade -3 (ref: lowest) } \\
\hline 2 nd $*$ Score in grade -3 & $\begin{array}{c}1.983^{* * *} \\
(0.206)\end{array}$ & $\begin{array}{c}1.492^{* * *} \\
(0.192)\end{array}$ & $\begin{array}{c}3.461^{* * *} \\
(0.161)\end{array}$ & $\begin{array}{c}2.450^{* * *} \\
(0.146)\end{array}$ \\
\hline 3 rd $*$ Score in grade -3 & $\begin{array}{c}2.918^{* * *} \\
(0.214)\end{array}$ & $\begin{array}{c}2.300^{* * *} \\
(0.196)\end{array}$ & $\begin{array}{c}4.120^{* * *} \\
(0.163)\end{array}$ & $\begin{array}{c}2.668^{* * *} \\
(0.150)\end{array}$ \\
\hline 4 th $*$ Score in grade -3 & $\begin{array}{c}2.365^{* * *} \\
(0.233)\end{array}$ & $\begin{array}{c}1.508^{* * *} \\
(0.204)\end{array}$ & $\begin{array}{c}4.979^{* * *} \\
(0.181)\end{array}$ & $\begin{array}{c}3.242^{* * *} \\
(0.161)\end{array}$ \\
\hline \multicolumn{5}{|c|}{ ESCS quartile * COVID cohort (ref: lowest) } \\
\hline 2nd * COVID cohort & $\begin{array}{c}-2.257^{* * *} \\
(0.289)\end{array}$ & $\begin{array}{c}-2.758^{* * *} \\
(0.261)\end{array}$ & $\begin{array}{c}-1.382^{* * *} \\
(0.206)\end{array}$ & $\begin{array}{c}-1.068^{* * *} \\
(0.181)\end{array}$ \\
\hline 3rd * COVID cohort & $\begin{array}{c}-2.560^{* * *} \\
(0.297)\end{array}$ & $\begin{array}{c}-1.703^{* * *} \\
(0.269)\end{array}$ & $\begin{array}{c}-1.454^{* * *} \\
(0.212)\end{array}$ & $\begin{array}{c}-0.843^{* * *} \\
(0.188)\end{array}$ \\
\hline 4 th $*$ COVID cohort & $\begin{array}{c}-2.891^{* * *} \\
(0.332)\end{array}$ & $\begin{array}{c}-1.949^{* * *} \\
(0.295)\end{array}$ & $\begin{array}{c}-2.501^{* * *} \\
(0.224)\end{array}$ & $\begin{array}{c}-0.977^{* * *} \\
(0.202)\end{array}$ \\
\hline \multicolumn{5}{|c|}{ ESCS quartile $*$ COVID cohort $*$ Score in grade -3 (ref: lowest) } \\
\hline 2 nd $*$ COVID cohort $*$ Score in grade -3 & $\begin{array}{c}-1.010^{* * *} \\
(0.292)\end{array}$ & $\begin{array}{l}-0.495 \\
(0.269)\end{array}$ & $\begin{array}{c}-0.832^{* * *} \\
(0.216)\end{array}$ & $\begin{array}{c}-0.689^{* * *} \\
(0.197)\end{array}$ \\
\hline 3 rd $*$ COVID cohort $*$ Score in grade -3 & $\begin{array}{c}-1.241^{* * *} \\
(0.301)\end{array}$ & $\begin{array}{l}-0.386 \\
(0.274)\end{array}$ & $\begin{array}{l}-0.308 \\
(0.221)\end{array}$ & $\begin{array}{l}-0.361 \\
(0.203)\end{array}$ \\
\hline 4 th $*$ COVID cohort $*$ Score in grade -3 & $\begin{array}{c}-0.977^{* *} \\
(0.323)\end{array}$ & $\begin{array}{l}0.696^{*} \\
(0.291)\end{array}$ & $\begin{array}{l}-0.337 \\
(0.233)\end{array}$ & $\begin{array}{c}-0.946^{* * *} \\
(0.214)\end{array}$ \\
\hline Constant & $\begin{array}{c}198.473^{* * *} \\
(1.413)\end{array}$ & $\begin{array}{c}186.809^{* * *} \\
(1.438)\end{array}$ & $\begin{array}{c}171.292^{* * *} \\
(0.880)\end{array}$ & $\begin{array}{c}180.022^{* * *} \\
(0.771)\end{array}$ \\
\hline Observations & 829120 & 823190 & 882330 & 887142 \\
\hline$R^{2}$ & 0.277 & 0.252 & 0.420 & 0.442 \\
\hline
\end{tabular}

Notes: The Covid cohort identifies students for whom the achievement outcome in grade 5 or grade 8 was measured in $2020-2021$. Scores in the previous INVALSI test are standardized to have a mean of zero and a standard deviation of one in their respective grades and cohorts. Standard errors obtained from regressions clustering students within classrooms they attended in the year where outcomes are measured. Regression models include province fixed effects.

Source: INVALSI 2015-2016, 2017-2018, 2018-2019 and 2020-2021 (grades 2, 5, 8). 
Table A6: Predicting grade 5 and grade 8 math and reading achievement, with gender triple interaction

\begin{tabular}{|c|c|c|c|c|}
\hline & \multicolumn{2}{|c|}{ Grade 5} & \multicolumn{2}{|c|}{ Grade 8} \\
\hline & Math & Reading & Math & Reading \\
\hline Score in grade -3 & $\begin{array}{c}17.495^{* * *} \\
(0.136)\end{array}$ & $\begin{array}{c}17.490^{* * *} \\
(0.115)\end{array}$ & $\begin{array}{c}19.949^{* * *} \\
(0.110)\end{array}$ & $\begin{array}{c}19.927^{* * *} \\
(0.092)\end{array}$ \\
\hline COVID cohort & $\begin{array}{c}2.017^{* * *} \\
(0.193)\end{array}$ & $\begin{array}{c}3.038^{* * *} \\
(0.168)\end{array}$ & $\begin{array}{c}-7.975^{* * *} \\
(0.121)\end{array}$ & $\begin{array}{c}-2.554^{* * *} \\
(0.105)\end{array}$ \\
\hline Female student & $\begin{array}{c}-3.385^{* * *} \\
(0.098)\end{array}$ & $\begin{array}{c}7.348^{* * *} \\
(0.101)\end{array}$ & $\begin{array}{c}-1.661^{* * *} \\
(0.095)\end{array}$ & $\begin{array}{c}5.575^{* * *} \\
(0.084)\end{array}$ \\
\hline \multicolumn{5}{|l|}{ ESCS quartile (ref: lowest) } \\
\hline 2nd & $\begin{array}{c}7.422^{* * *} \\
(0.140)\end{array}$ & $\begin{array}{c}7.290^{* * *} \\
(0.128)\end{array}$ & $\begin{array}{c}7.030^{* * *} \\
(0.100)\end{array}$ & $\begin{array}{c}6.451^{* * *} \\
(0.088)\end{array}$ \\
\hline $3 r d$ & $\begin{array}{c}10.734^{* * *} \\
(0.144)\end{array}$ & $\begin{array}{c}10.978^{* * *} \\
(0.133)\end{array}$ & $\begin{array}{c}10.837^{* * *} \\
(0.107)\end{array}$ & $\begin{array}{c}9.851^{* * *} \\
(0.095)\end{array}$ \\
\hline 4 th & $\begin{array}{c}14.279^{* * *} \\
(0.160)\end{array}$ & $\begin{array}{c}14.922^{* * *} \\
(0.149)\end{array}$ & $\begin{array}{c}16.660^{* * *} \\
(0.122)\end{array}$ & $\begin{array}{c}15.288^{* * *} \\
(0.105)\end{array}$ \\
\hline \multicolumn{5}{|l|}{ Interactions } \\
\hline Score in grade $-3 *$ COVID cohort & $\begin{array}{c}3.391^{* * *} \\
(0.172)\end{array}$ & $\begin{array}{c}-2.016^{* * *} \\
(0.160)\end{array}$ & $\begin{array}{c}4.031^{* * *} \\
(0.125)\end{array}$ & $\begin{array}{c}1.611^{* * *} \\
(0.110)\end{array}$ \\
\hline Gender $*$ Score in grade -3 & $\begin{array}{c}-2.054^{* * *} \\
(0.112)\end{array}$ & $\begin{array}{c}-1.358^{* * *} \\
(0.107)\end{array}$ & $\begin{array}{c}-2.681^{* * *} \\
(0.111)\end{array}$ & $\begin{array}{l}0.284^{* *} \\
(0.100)\end{array}$ \\
\hline Gender * COVID cohort & $\begin{array}{c}-0.423^{* *} \\
(0.150)\end{array}$ & $\begin{array}{c}-2.365^{* * *} \\
(0.144)\end{array}$ & $\begin{array}{c}2.234^{* * *} \\
(0.134)\end{array}$ & $\begin{array}{c}-1.487^{* * *} \\
(0.119)\end{array}$ \\
\hline Gender $*$ COVID cohort $*$ Score in grade -3 & $\begin{array}{c}0.649^{* * *} \\
(0.164)\end{array}$ & $\begin{array}{c}1.050^{* * *} \\
(0.154)\end{array}$ & $\begin{array}{c}0.737^{* * *} \\
(0.148)\end{array}$ & $\begin{array}{l}-0.076 \\
(0.135)\end{array}$ \\
\hline Constant & $\begin{array}{c}199.504^{* * *} \\
(1.414)\end{array}$ & $\begin{array}{c}187.189^{* * *} \\
(1.437)\end{array}$ & $\begin{array}{c}173.196^{* * *} \\
(0.882)\end{array}$ & $\begin{array}{c}180.584^{* * *} \\
(0.768)\end{array}$ \\
\hline $\begin{array}{l}\text { Observations } \\
R^{2}\end{array}$ & $\begin{array}{c}829120 \\
0.276\end{array}$ & $\begin{array}{c}823190 \\
0.252\end{array}$ & $\begin{array}{c}882330 \\
0.419\end{array}$ & $\begin{array}{c}887142 \\
0.441\end{array}$ \\
\hline
\end{tabular}

Notes: The Covid cohort identifies students for whom the achievement outcome in grade 5 or grade 8 was measured in 2020-2021. Scores in the previous INVALSI test are standardized to have a mean of zero and a standard deviation of one in their respective grades and cohorts. Standard errors obtained from regressions clustering students within classrooms they attended in the year where outcomes are measured. Regression models include province fixed effects.

Source: INVALSI 2015-2016, 2017-2018, 2018-2019 and 2020-2021 (grades 2, 5, 8). 
Figure A1: The impact of being in the Covid cohort on math achievement in grade 5, by province
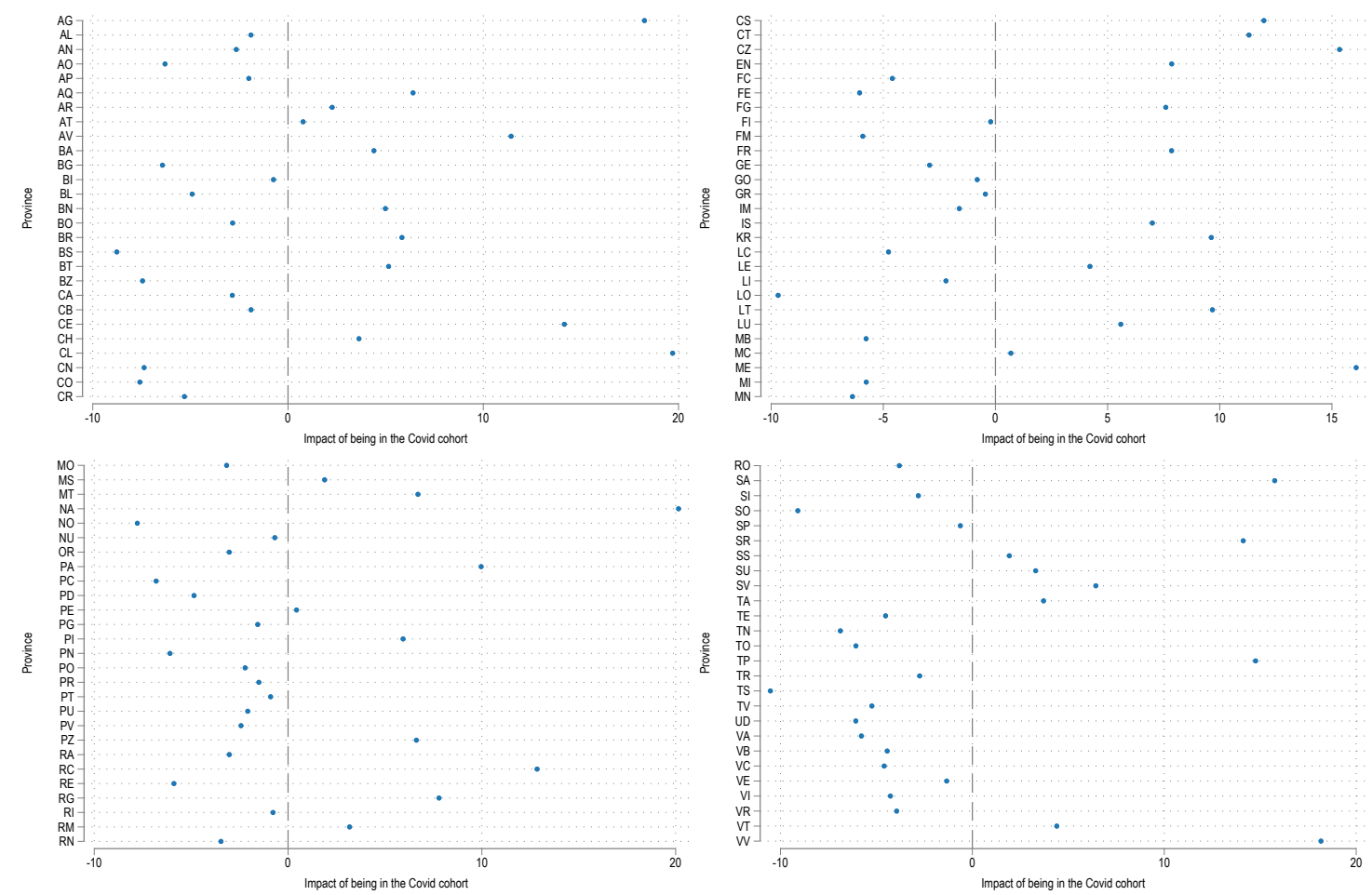

Notes: Results from models comparing the Covid cohorts and the Non-Covid cohorts controlling for students' gender, standardized scores in the previous INVALSI test, and the ESCS indicator, run separately for each province. The Covid cohort identifies students for whom the achievement outcome in grade 5 or grade 8 was measured in 2020-2021. Scores in the previous INVALSI test are standardized to have a mean of zero and a standard deviation of one in their respective grades and cohorts.

Source: INVALSI 2015-2016, 2017-2018, 2018-2019 and 2020-2021 (grades 2, 5, 8). 
Figure A2: The impact of being in the Covid cohort on math achievement in grade 8, by province
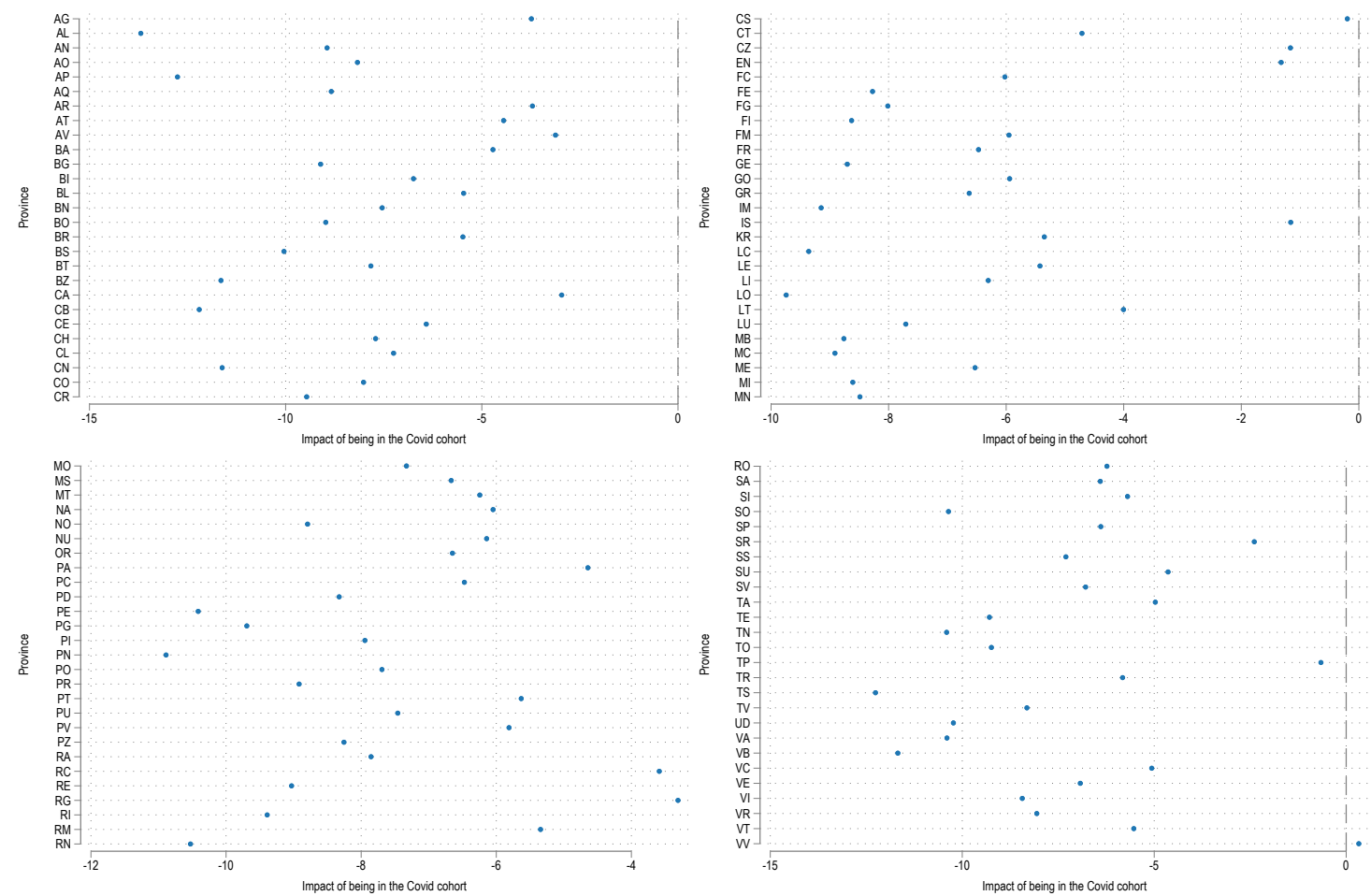

Notes: Results from models comparing the Covid cohorts and the Non-Covid cohorts controlling for students' gender, standardized scores in the previous INVALSI test, and the ESCS indicator, run separately for each province. The Covid cohort identifies students for whom the achievement outcome in grade 5 or grade 8 was measured in 2020-2021. Scores in the previous INVALSI test are standardized to have a mean of zero and a standard deviation of one in their respective grades and cohorts.

Source: INVALSI 2015-2016, 2017-2018, 2018-2019 and 2020-2021 (grades 2, 5, 8). 
Figure A3: The impact of being in the Covid cohort and previous math scores on math achievement in grade 5 , by province
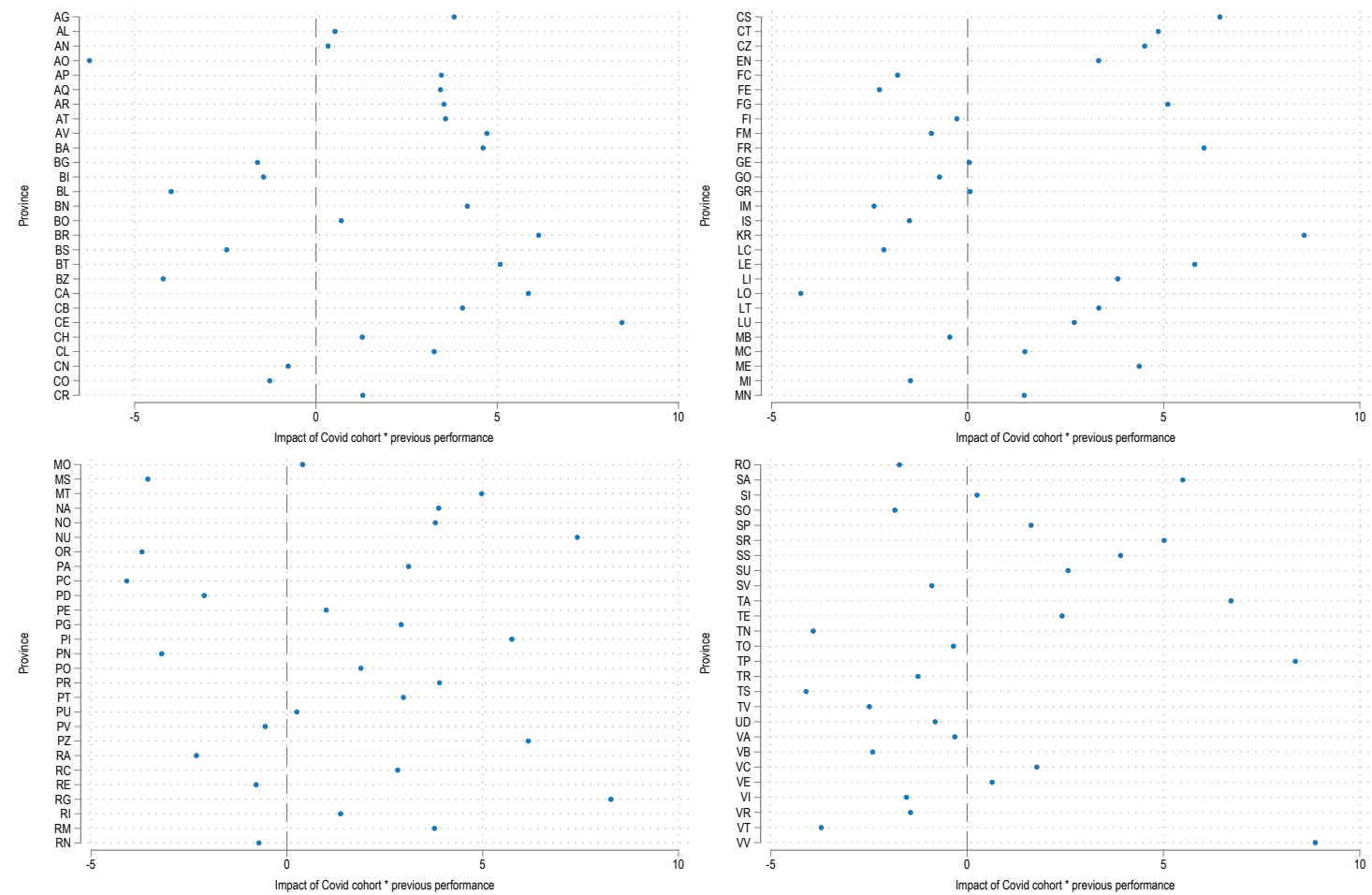

Notes: Results from models comparing the Covid cohorts and the Non-Covid cohorts controlling for students' gender, standardized scores in the previous INVALSI test, the ESCS indicator and the interaction between an indicator for being in the Covid cohort and standardized scores in the previous INVALSI test, run separately for each province. The Covid cohort identifies students for whom the achievement outcome in grade 5 or grade 8 was measured in 2020-2021. Scores in the previous INVALSI test are standardized to have a mean of zero and a standard deviation of one in their respective grades and cohorts.

Source: INVALSI 2015-2016, 2017-2018, 2018-2019 and 2020-2021 (grades 2, 5, 8). 
Figure A4: The impact of being in the Covid cohort and previous math scores on math achievement in grade 8 , by province
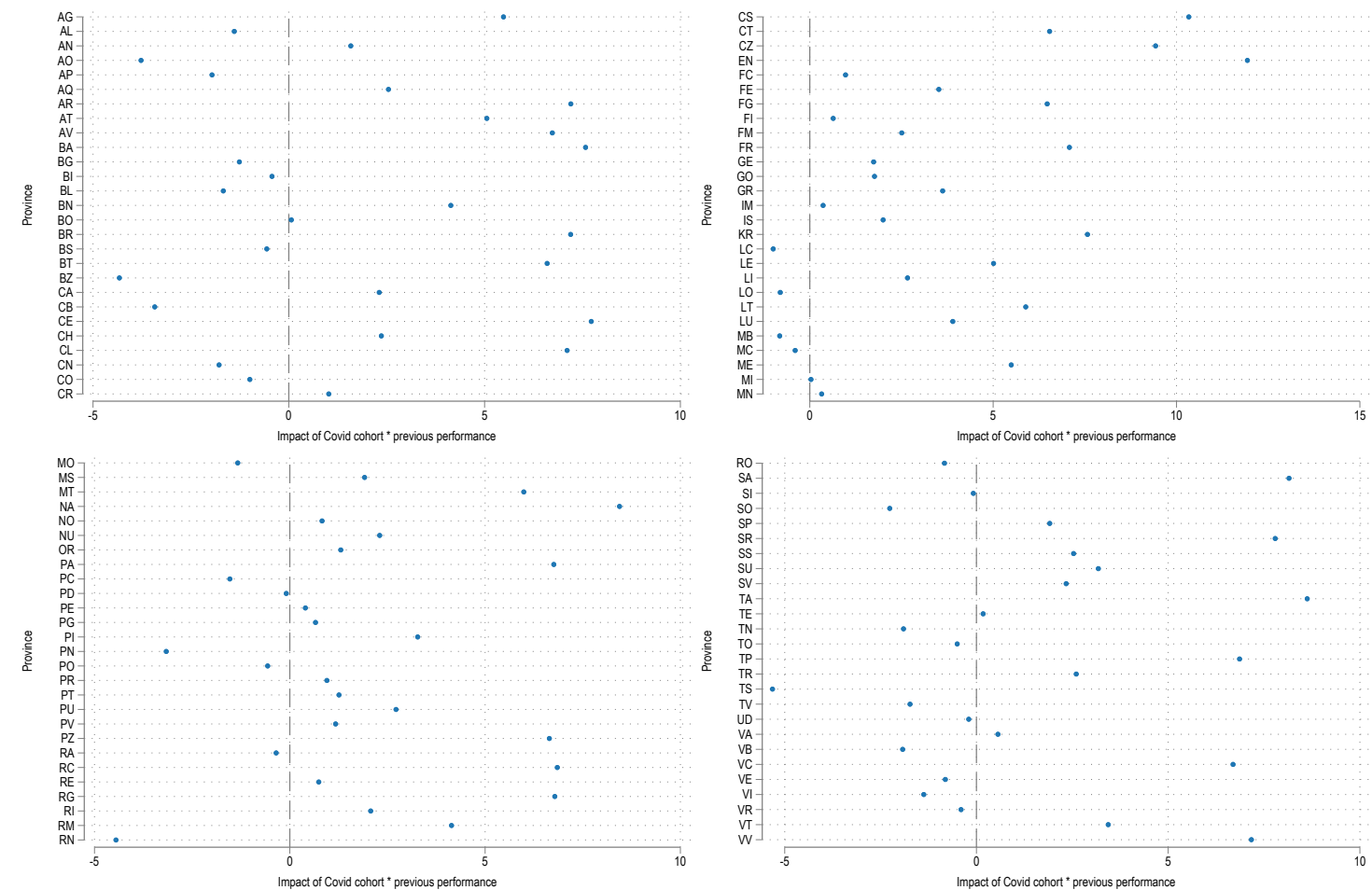

Notes: Results from models comparing the Covid cohorts and the Non-Covid cohorts controlling for students' gender, standardized scores in the previous INVALSI test, the ESCS indicator and the interaction between an indicator for being in the Covid cohort and standardized scores in the previous INVALSI test, run separately for each province. The Covid cohort identifies students for whom the achievement outcome in grade 5 or grade 8 was measured in $2020-2021$. Scores in the previous INVALSI test are standardized to have a mean of zero and a standard deviation of one in their respective grades and cohorts.

Source: INVALSI 2015-2016, 2017-2018, 2018-2019 and 2020-2021 (grades 2, 5, 8). 
Figure A5: The effect of being in the Covid cohorts on math achievement by SES in grades 5 and 8

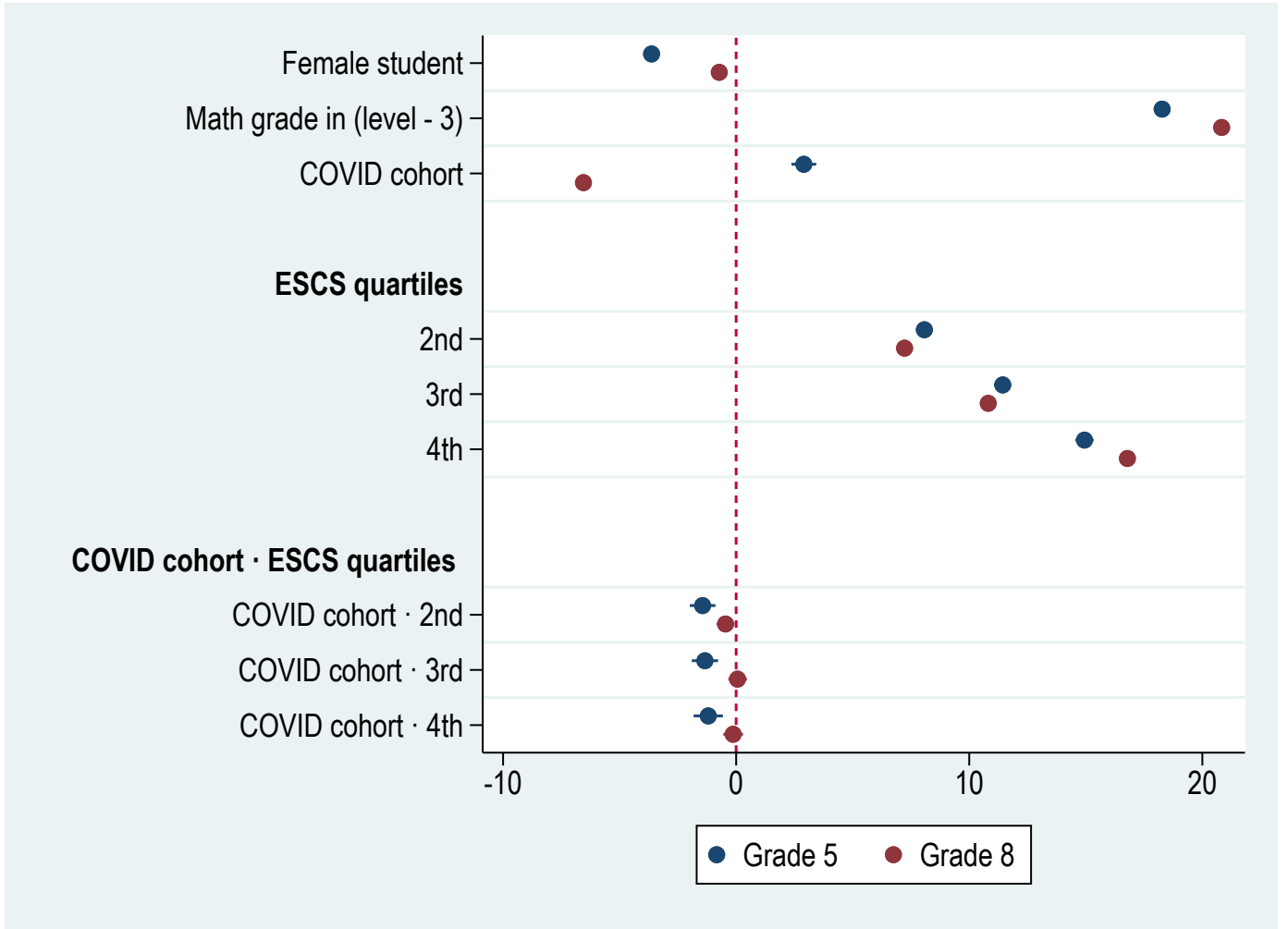

Notes: The Covid cohort identifies students for whom the achievement outcome in grade 5 or grade 8 was measured in 2020-2021. Scores in the previous INVALSI test are standardized to have a mean of zero and a standard deviation of one in their respective grades and cohorts. Standard errors obtained from regressions clustering students within classrooms they attended in the year where outcomes are measured. Regression models include province fixed effects.

Source: INVALSI 2015-2016, 2017-2018, 2018-2019 and 2020-2021 (grades 2, 5, 8). 
Figure A6: The effect of being in the Covid cohorts on math achievement by gender in grades 5 and 8

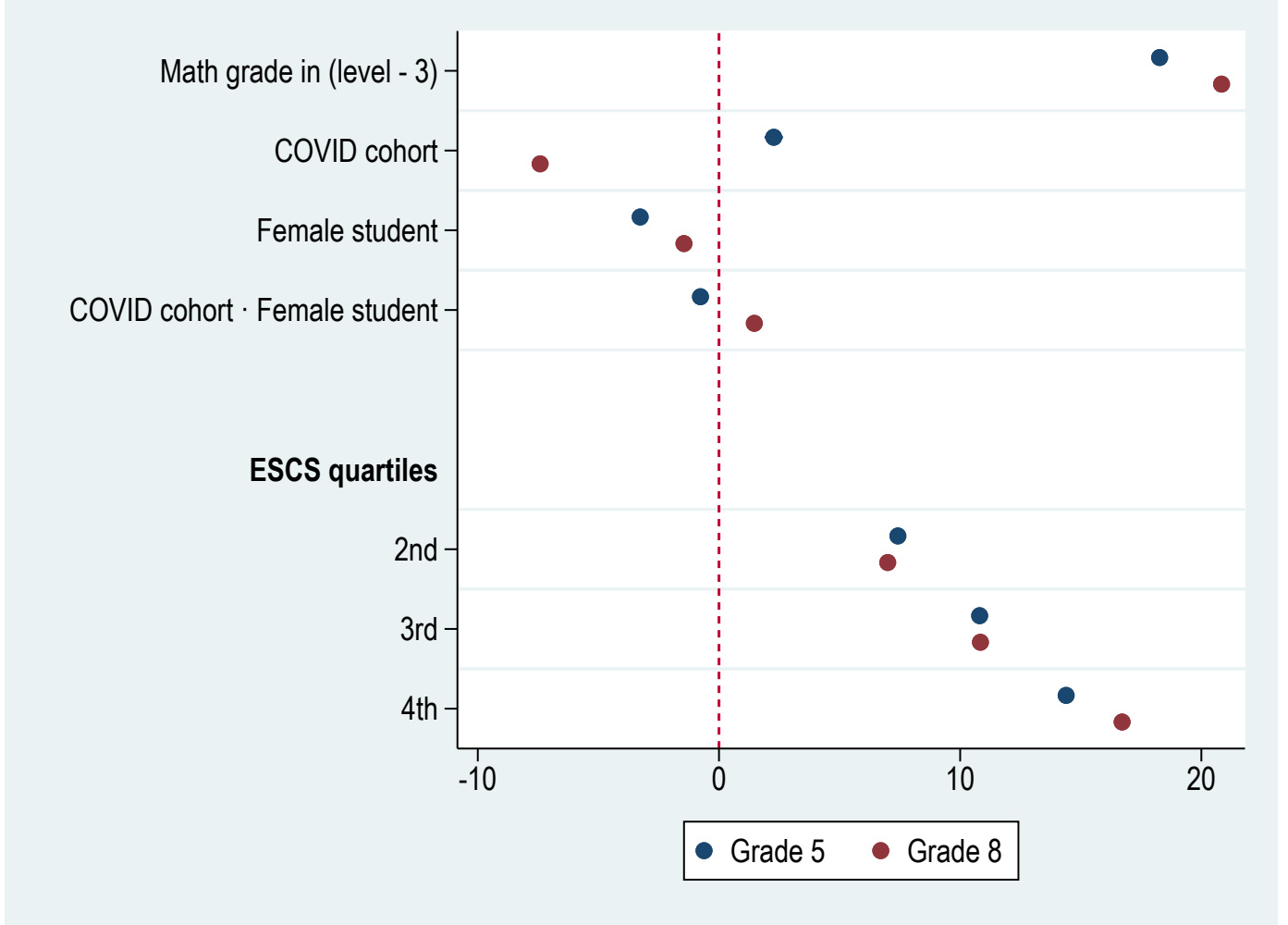

Notes: The Covid cohort identifies students for whom the achievement outcome in grade 5 or grade 8 was measured in 2020-2021. Scores in the previous INVALSI test are standardized to have a mean of zero and a standard deviation of one in their respective grades and cohorts. Standard errors obtained from regressions clustering students within classrooms they attended in the year where outcomes are measured. Regression models include province fixed effects.

Source: INVALSI 2015-2016, 2017-2018, 2018-2019 and 2020-2021 (grades 2, 5, 8). 
Figure A7: The impact of being in the Covid cohort and previous math scores on math achievement in grade 5 , by parental educational attainment
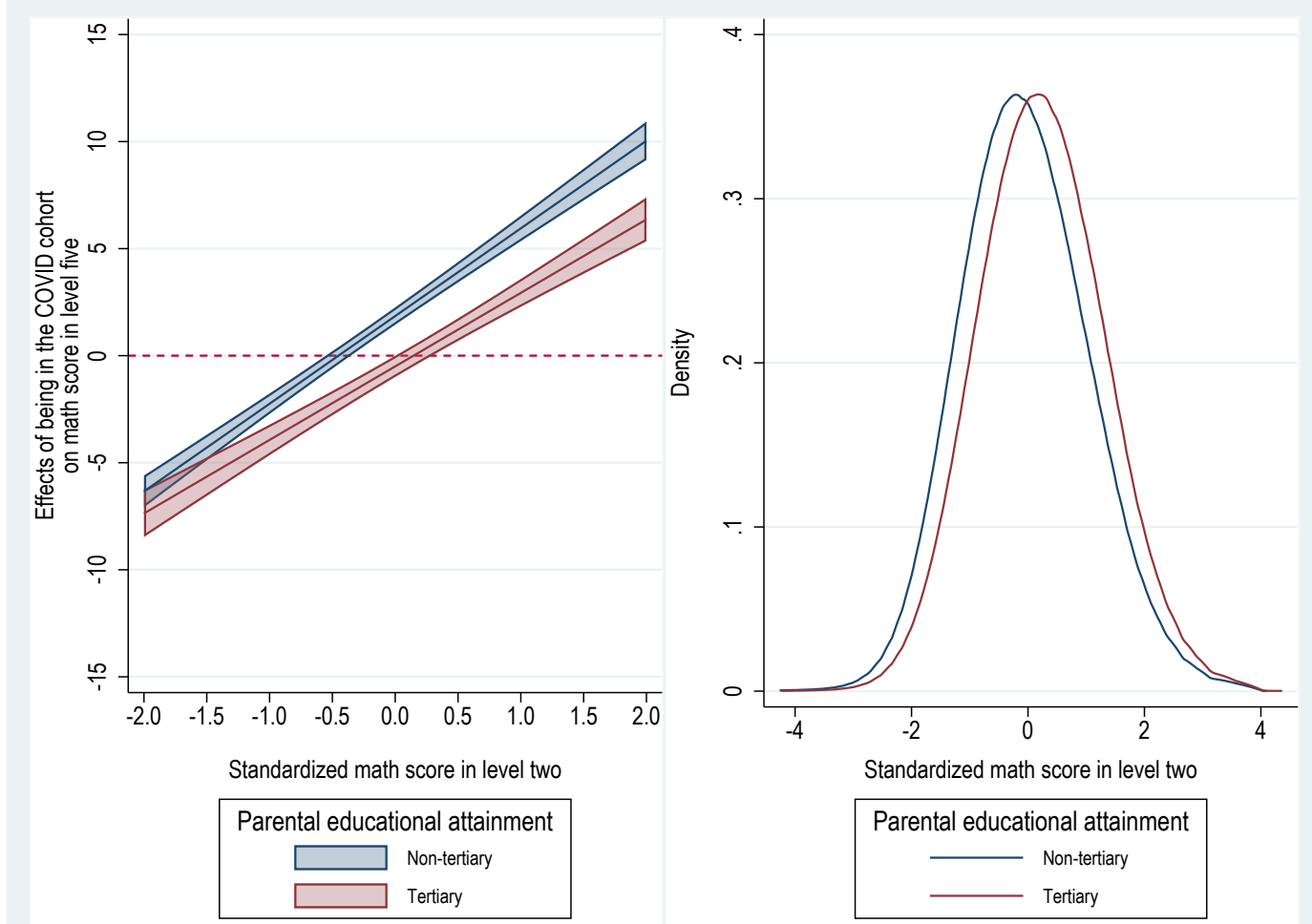

Parental educational attainment

Non-tertiary

Tertiary

Notes:Results from models comparing the Covid cohorts and the Non-Covid cohorts controlling for students' gender, standardized scores in the previous INVALSI test, a binary indicator for parental educational attainment, province fixed effects, as well as the interaction between an indicator for being in the Covid cohort, standardized scores in the previous INVALSI test and the binary indicator for parental educational attainment. The Covid cohort identifies students for whom the achievement outcome in grade 5 or grade 8 was measured in 2020-2021. Scores in the previous INVALSI test are standardized to have a mean of zero and a standard deviation of one in their respective grades and cohorts. Results are presented with $95 \%$ confidence intervals obtained by clustering students within classrooms they attended in the year where outcomes are measured.

Source: INVALSI 2015-2016, 2017-2018, 2018-2019 and 2020-2021 (grades 2, 5, 8). 
Figure A8: The impact of being in the Covid cohort and previous math scores on math achievement in grade 8 , by parental educational attainment
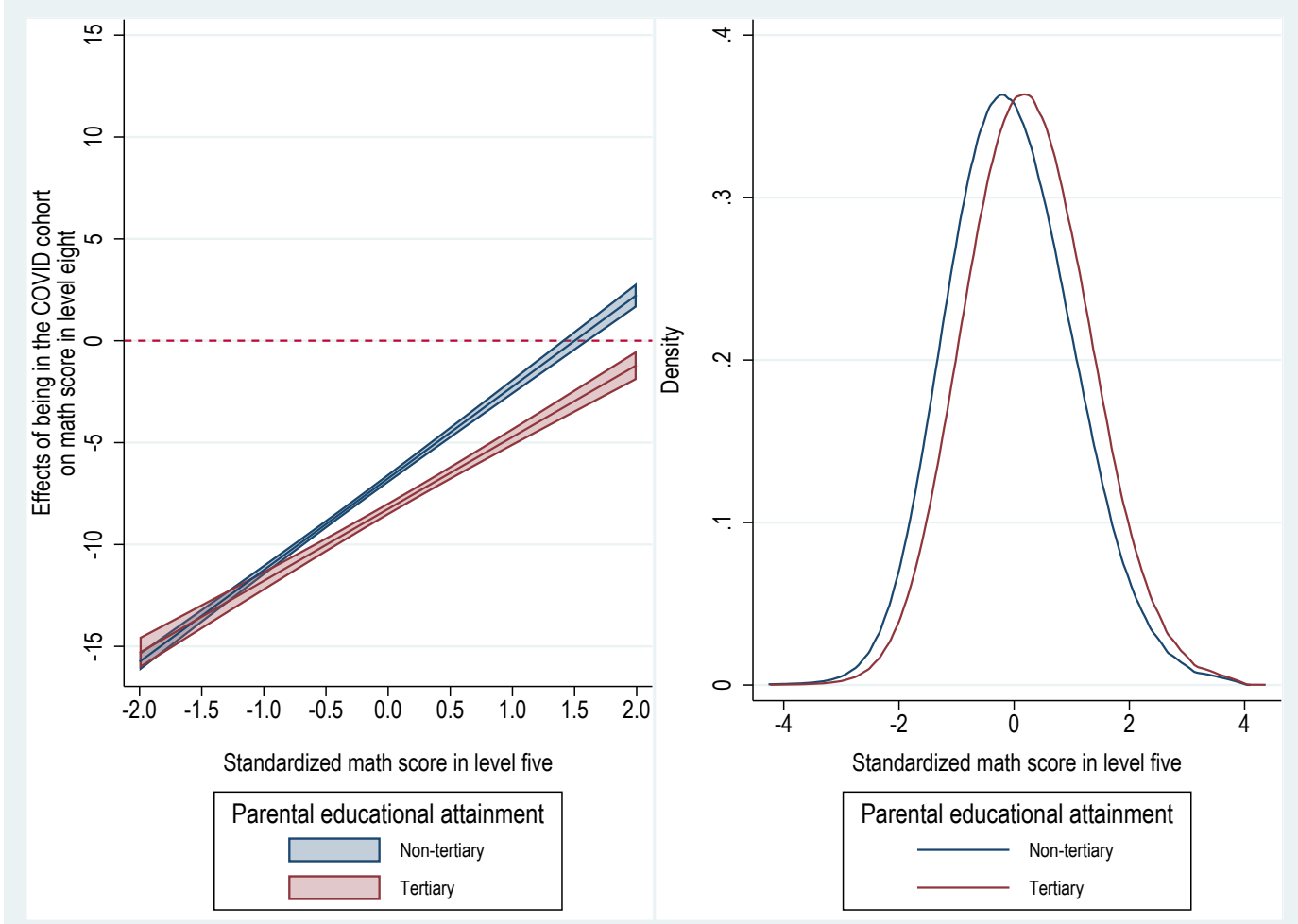

Notes:Results from models comparing the Covid cohorts and the Non-Covid cohorts controlling for students' gender, standardized scores in the previous INVALSI test, a binary indicator for parental educational attainment, province fixed effects, as well as the interaction between an indicator for being in the Covid cohort, standardized scores in the previous INVALSI test and the binary indicator for parental educational attainment. The Covid cohort identifies students for whom the achievement outcome in grade 5 or grade 8 was measured in 2020-2021. Scores in the previous INVALSI test are standardized to have a mean of zero and a standard deviation of one in their respective grades and cohorts. Results are presented with $95 \%$ confidence intervals obtained by clustering students within classrooms they attended in the year where outcomes are measured.

Source: INVALSI 2015-2016, 2017-2018, 2018-2019 and 2020-2021 (grades 2, 5, 8). 
Figure A9: The impact of being in the Covid cohort on reading achievement in grade 5, by province
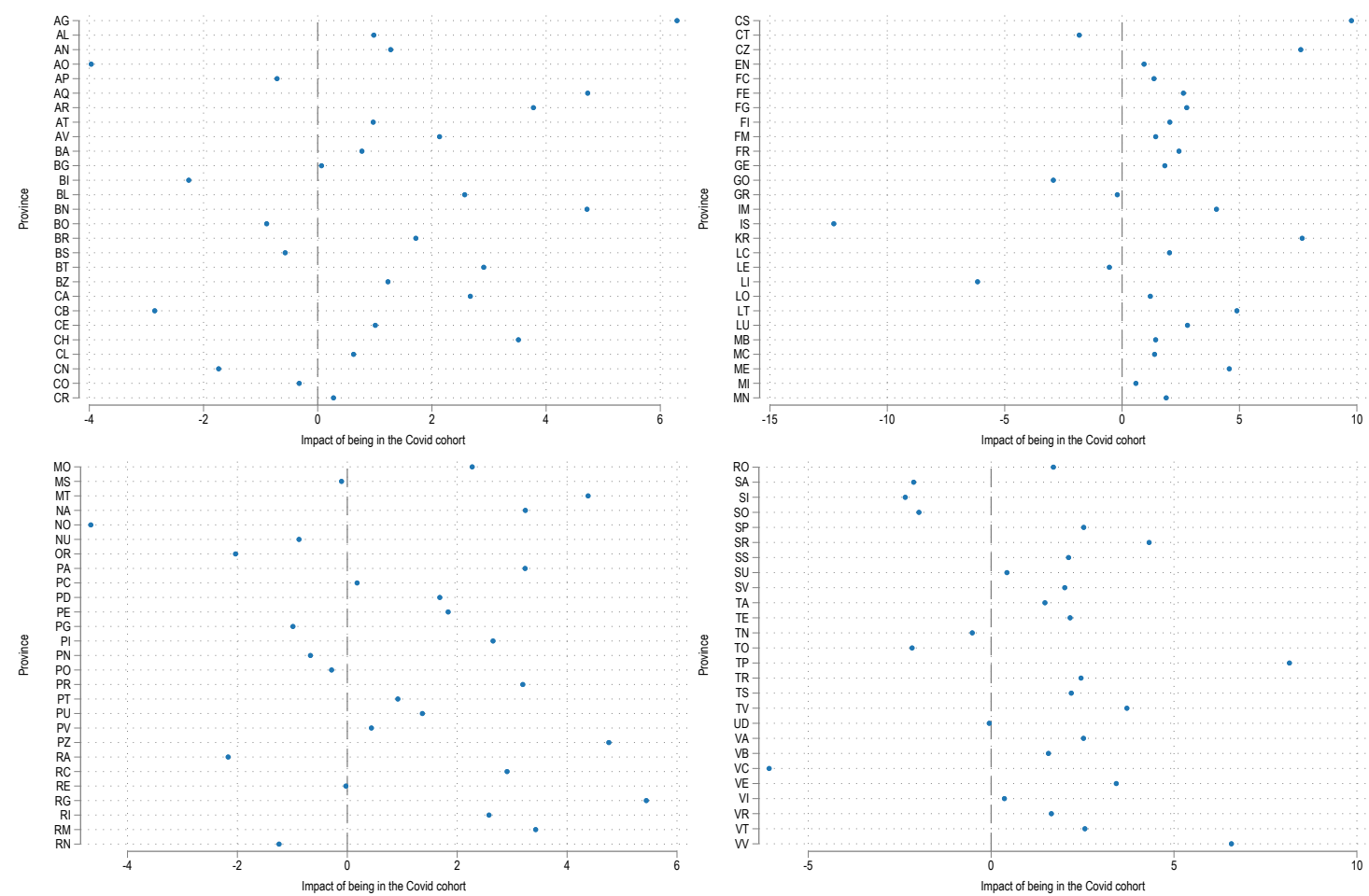

Notes: Results from models comparing the Covid cohorts and the Non-Covid cohorts controlling for students' gender, standardized scores in the previous INVALSI test, and the ESCS indicator, run separately for each province. The Covid cohort identifies students for whom the achievement outcome in grade 5 or grade 8 was measured in 2020-2021. Scores in the previous INVALSI test are standardized to have a mean of zero and a standard deviation of one in their respective grades and cohorts.

Source: INVALSI 2015-2016, 2017-2018, 2018-2019 and 2020-2021 (grades 2, 5, 8). 
Figure A10: The impact of being in the Covid cohort on reading achievement in grade 8, by province
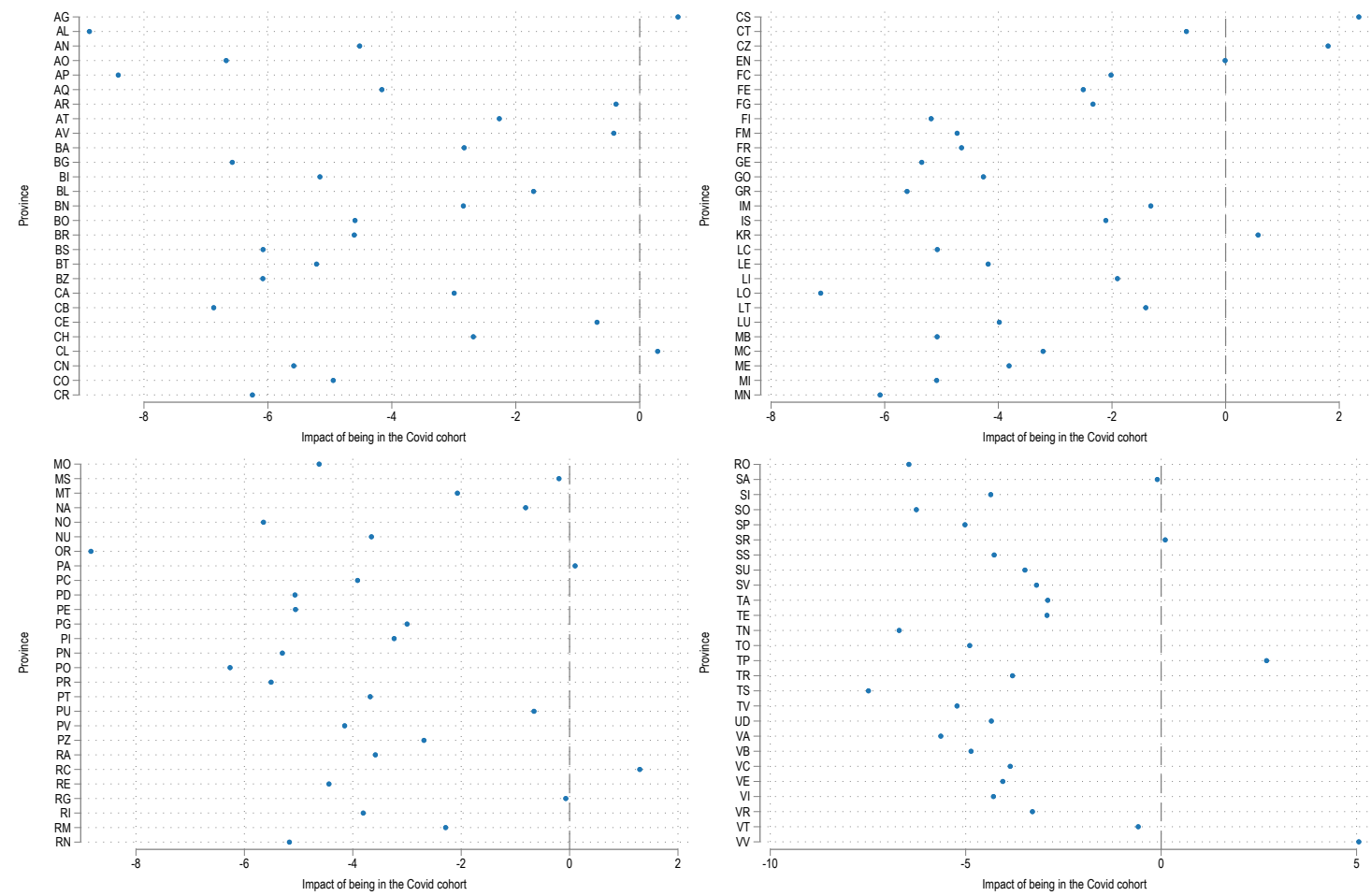

Notes: Results from models comparing the Covid cohorts and the Non-Covid cohorts controlling for students' gender, standardized scores in the previous INVALSI test, and the ESCS indicator, run separately for each province. The Covid cohort identifies students for whom the achievement outcome in grade 5 or grade 8 was measured in 2020-2021. Scores in the previous INVALSI test are standardized to have a mean of zero and a standard deviation of one in their respective grades and cohorts.

Source: INVALSI 2015-2016, 2017-2018, 2018-2019 and 2020-2021 (grades 2, 5, 8). 
Figure A11: The impact of being in the Covid cohort and previous reading scores on reading achievement in grade 5 , by province
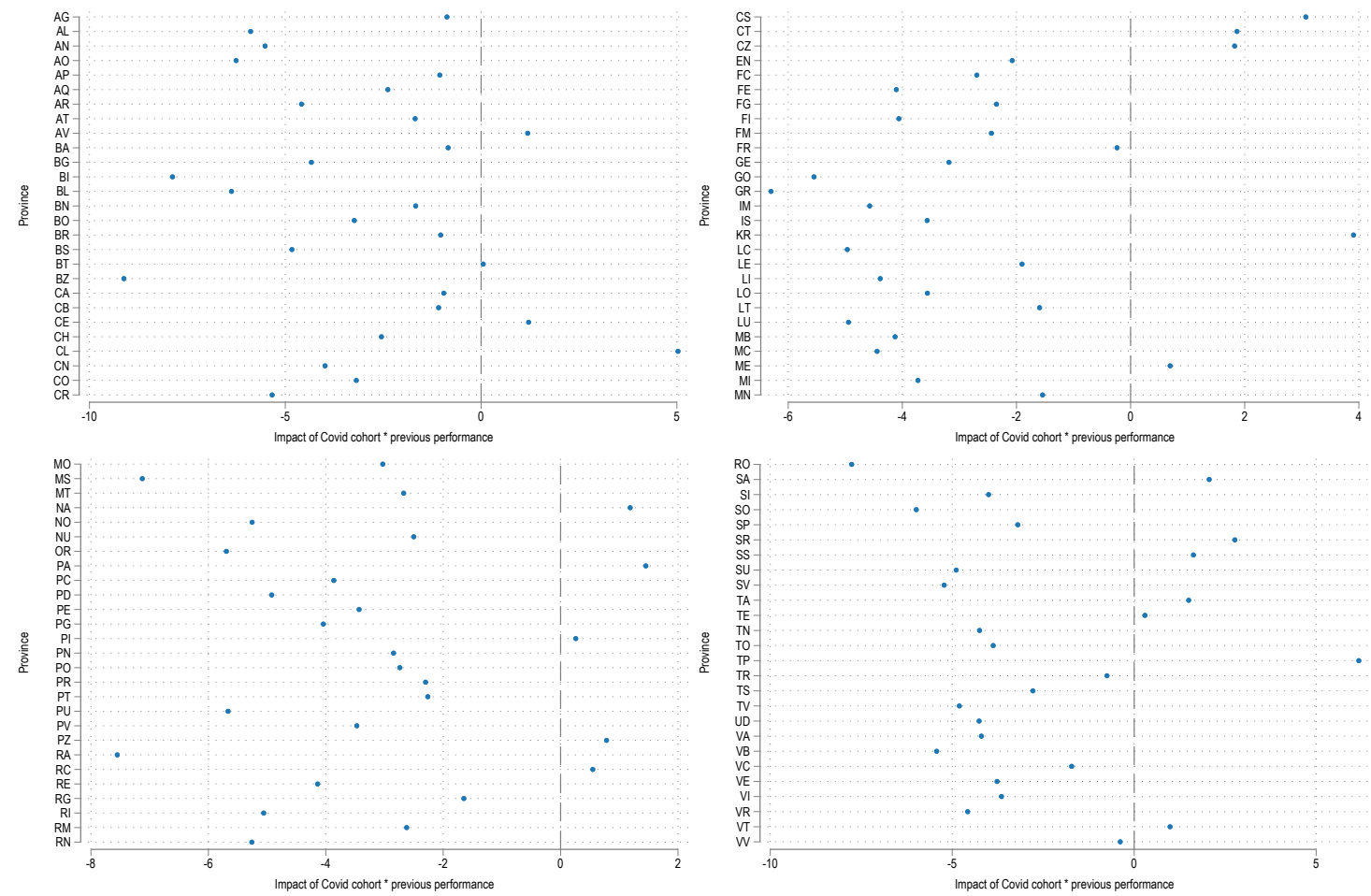

Notes: Results from models comparing the Covid cohorts and the Non-Covid cohorts controlling for students' gender, standardized scores in the previous INVALSI test, the ESCS indicator and the interaction between an indicator for being in the Covid cohort and standardized scores in the previous INVALSI test, run separately for each province. The Covid cohort identifies students for whom the achievement outcome in grade 5 or grade 8 was measured in 2020-2021. Scores in the previous INVALSI test are standardized to have a mean of zero and a standard deviation of one in their respective grades and cohorts.

Source: INVALSI 2015-2016, 2017-2018, 2018-2019 and 2020-2021 (grades 2, 5, 8). 
Figure A12: The impact of being in the Covid cohort and previous reading scores on reading achievement in grade 8 , by province
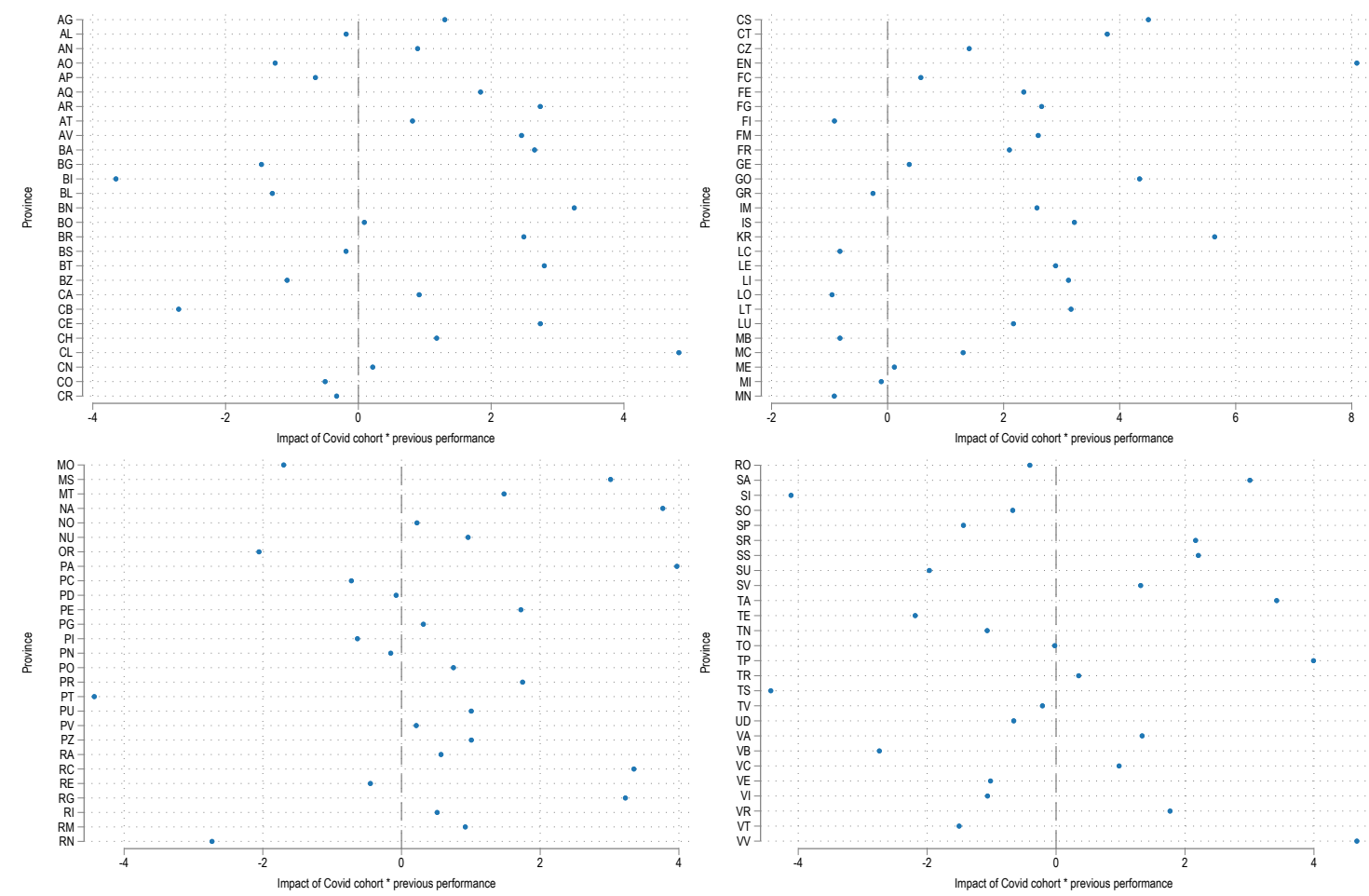

Notes: Results from models comparing the Covid cohorts and the Non-Covid cohorts controlling for students' gender, standardized scores in the previous INVALSI test, the ESCS indicator and the interaction between an indicator for being in the Covid cohort and standardized scores in the previous INVALSI test, run separately for each province. The Covid cohort identifies students for whom the achievement outcome in grade 5 or grade 8 was measured in 2020-2021. Scores in the previous INVALSI test are standardized to have a mean of zero and a standard deviation of one in their respective grades and cohorts.

Source: INVALSI 2015-2016, 2017-2018, 2018-2019 and 2020-2021 (grades 2, 5, 8). 
Figure A13: The effect of being in the Covid cohorts on reading achievement by SES in grades 5 and 8

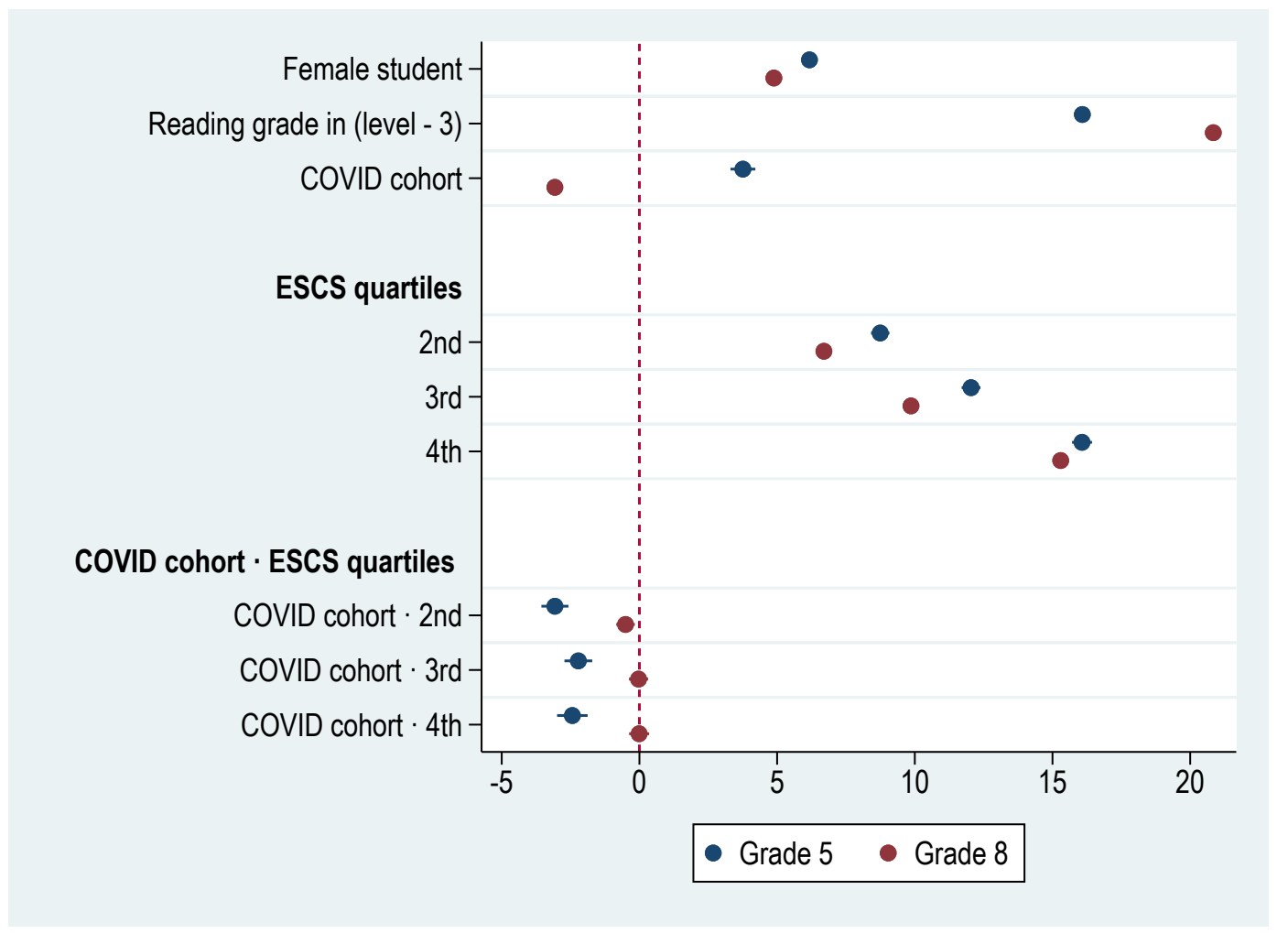

Notes: The Covid cohort identifies students for whom the achievement outcome in grade 5 or grade 8 was measured in 2020-2021. Scores in the previous INVALSI test are standardized to have a mean of zero and a standard deviation of one in their respective grades and cohorts. Standard errors obtained from regressions clustering students within classrooms they attended in the year where outcomes are measured. Regression models include province fixed effects.

Source: INVALSI 2015-2016, 2017-2018, 2018-2019 and 2020-2021 (grades 2, 5, 8). 
Figure A14: The effect of being in the Covid cohorts on reading achievement by gender in grades 5 and 8

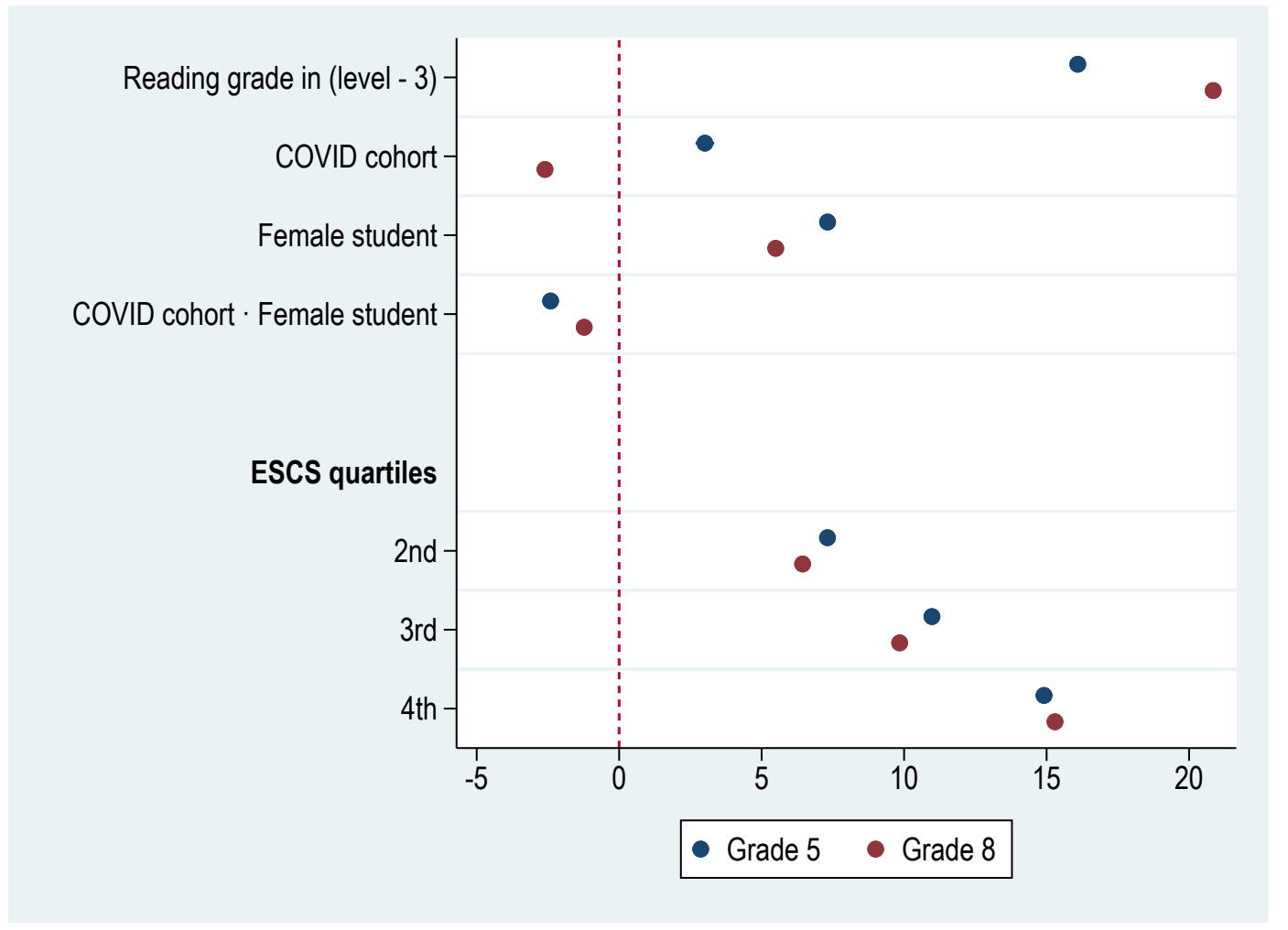

Notes: The Covid cohort identifies students for whom the achievement outcome in grade 5 or grade 8 was measured in 2020-2021. Scores in the previous INVALSI test are standardized to have a mean of zero and a standard deviation of one in their respective grades and cohorts. Standard errors obtained from regressions clustering students within classrooms they attended in the year where outcomes are measured. Regression models include province fixed effects.

Source: INVALSI 2015-2016, 2017-2018, 2018-2019 and 2020-2021 (grades 2, 5, 8). 
Figure A15: The impact of being in the Covid cohort and previous reading scores on reading achievement in grade 5 , by parental educational attainment

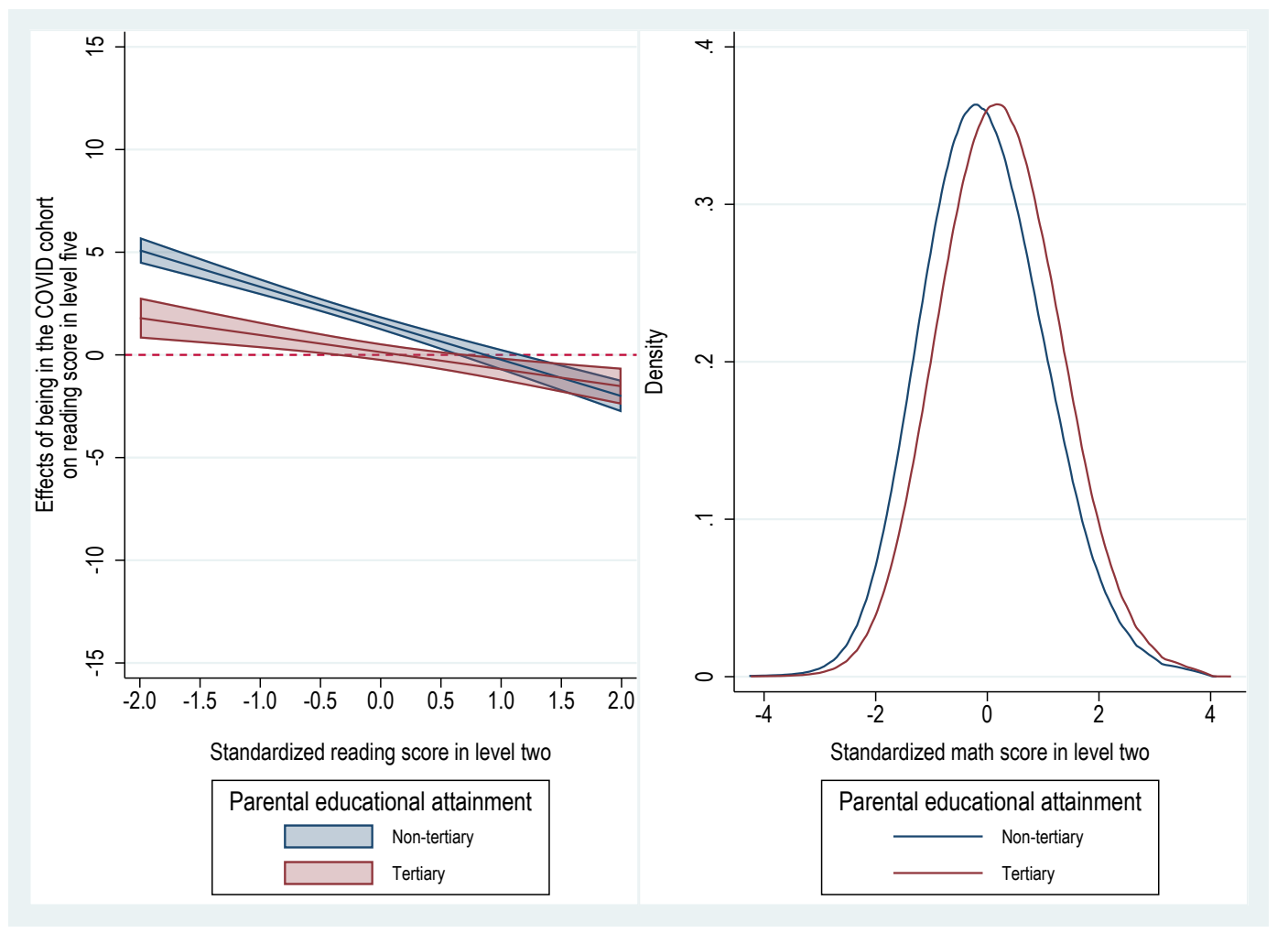

Notes:Results from models comparing the Covid cohorts and the Non-Covid cohorts controlling for students' gender, standardized scores in the previous INVALSI test, a binary indicator for parental educational attainment, province fixed effects, as well as the interaction between an indicator for being in the Covid cohort, standardized scores in the previous INVALSI test and the binary indicator for parental educational attainment. The Covid cohort identifies students for whom the achievement outcome in grade 5 or grade 8 was measured in 2020-2021. Scores in the previous INVALSI test are standardized to have a mean of zero and a standard deviation of one in their respective grades and cohorts. Results are presented with $95 \%$ confidence intervals obtained by clustering students within classrooms they attended in the year where outcomes are measured.

Source: INVALSI 2015-2016, 2017-2018, 2018-2019 and 2020-2021 (grades 2, 5, 8). 
Figure A16: The impact of being in the Covid cohort and previous reading scores on reading achievement in grade 8 , by parental educational attainment

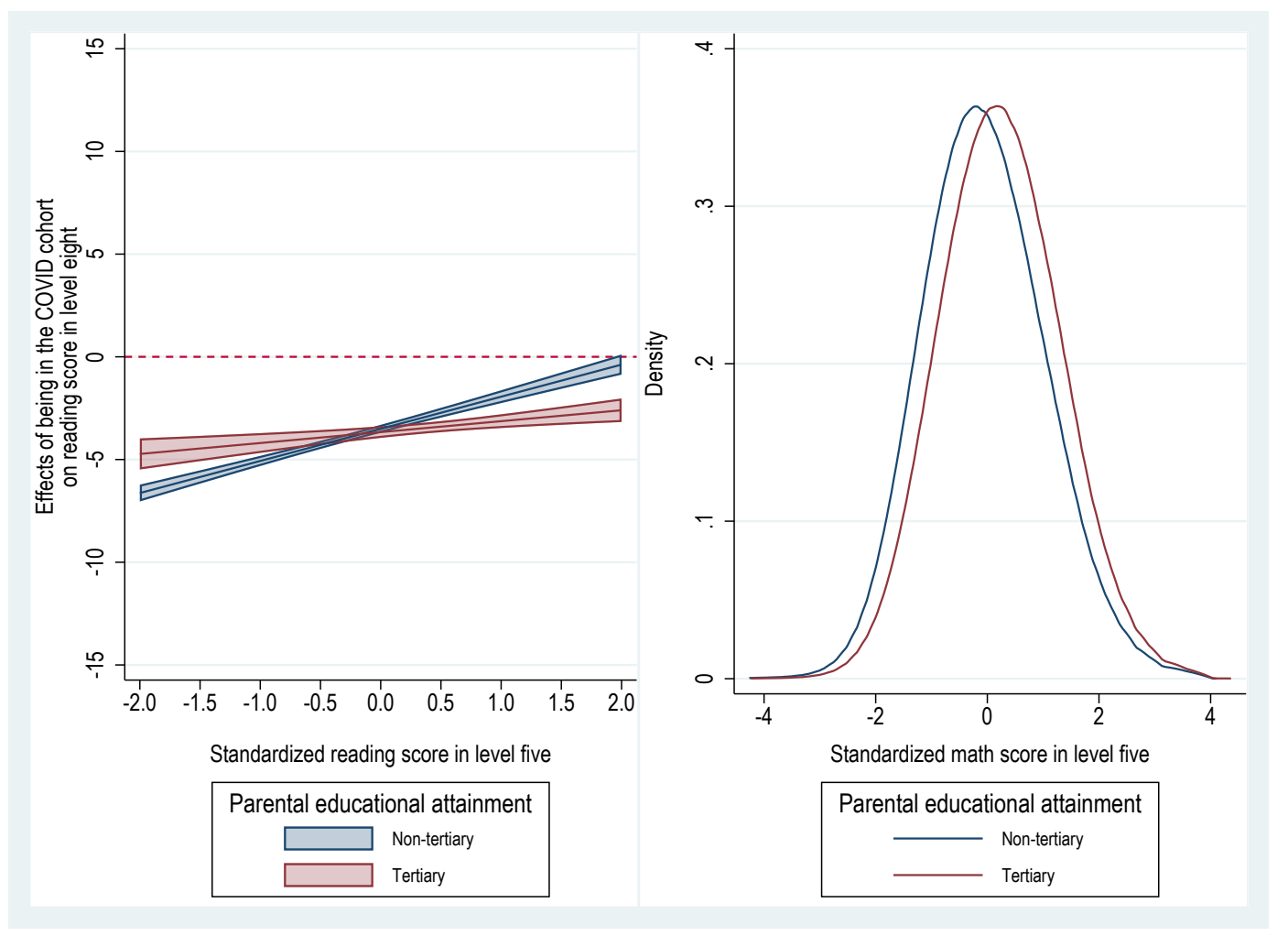

Notes:Results from models comparing the Covid cohorts and the Non-Covid cohorts controlling for students' gender, standardized scores in the previous INVALSI test, a binary indicator for parental educational attainment, province fixed effects, as well as the interaction between an indicator for being in the Covid cohort, standardized scores in the previous INVALSI test and the binary indicator for parental educational attainment. The Covid cohort identifies students for whom the achievement outcome in grade 5 or grade 8 was measured in 2020-2021. Scores in the previous INVALSI test are standardized to have a mean of zero and a standard deviation of one in their respective grades and cohorts. Results are presented with $95 \%$ confidence intervals obtained by clustering students within classrooms they attended in the year where outcomes are measured.

Source: INVALSI 2015-2016, 2017-2018, 2018-2019 and 2020-2021 (grades 2, 5, 8). 